\title{
Development of highly selective ligands for separations of actinides from lanthanides in the nuclear fuel cycle
}

Article

Accepted Version

Lewis, F., Hudson, M. J. and Harwood, L. (2011) Development of highly selective ligands for separations of actinides from lanthanides in the nuclear fuel cycle. Synlett, 2011 (18). pp. 2609-2632. ISSN 1437-2096 doi: https://doi.org/10.1055/s0030-1289557 Available at https://centaur.reading.ac.uk/24666/

It is advisable to refer to the publisher's version if you intend to cite from the work. See Guidance on citing.

To link to this article DOI: http://dx.doi.org/10.1055/s-0030-1289557

Publisher: Thieme Publishing

All outputs in CentAUR are protected by Intellectual Property Rights law, including copyright law. Copyright and IPR is retained by the creators or other copyright holders. Terms and conditions for use of this material are defined in the End User Agreement.

www.reading.ac.uk/centaur 
Central Archive at the University of Reading

Reading's research outputs online 


\title{
Development of Highly Selective Ligands for Separations of Actinides from Lanthanides in the Nuclear Fuel Cycle
}

\author{
Frank W. Lewis, Michael J. Hudson, Laurence M. Harwood* \\ School of Chemistry, University of Reading, Whiteknights, Reading RG6 6AD, Berkshire, United Kingdom \\ Fax: +44 (0) 1183786121 \\ E-mail: 1.m.harwood@ reading.ac.uk \\ Received: The date will be inserted once the manuscript is accepted. \\ Dedication - We dedicate this paper to the memory of Dr. Charles Madic.
}

\begin{abstract}
This account summarises recent work by ourselves and others on the development of ligands for the separation of actinides from lanthanides contained in nuclear waste streams in the context of a future European strategy for nuclear waste management. The current status of actinide/lanthanide separations worldwide is briefly discussed and the synthesis, development and testing of different classes of soft $\mathrm{N}$ - and Sdonor heterocyclic ligands in Europe over the last 20 years is presented. This work led to the current benchmark ligand that displays many of the desirable qualities for industrial use. The improvement of radiolytic stability through ligand design is also discussed.

1 Introduction and Background

2 Dithiophosphinic Acids

3 TERPY and Related Ligands

4 TPTZ and Related Ligands

5 BODO and Related Ligands

6 Podant Ligands

7 BTP and Related Ligands

8 BTBP and Related Ligands

9 Improving Radiolytic Stability through Ligand Design

10 Conclusions and Outlook
\end{abstract}

Key words: americium, heterocycles, ligands, actinides, nitrogen, solvent extraction, europium, separation, lanthanides

\section{Introduction and Background}

The generation of electricity through nuclear power is becoming increasingly important in order to meet future energy demands while minimizing the production of greenhouse gases. ${ }^{1}$ As a result, the inventory of nuclear waste worldwide and thus its environmental burden will continue to increase. ${ }^{2}$ However, an effective strategy for the improved safe long-term management and disposal of the waste remains to be further studied.

The spent nuclear fuel produced by a typical light water reactor is composed of uranium and short-lived fission products such as lanthanides (>98.5 wt \%) which do not pose a long term hazard, together with plutonium and the minor actinides $\mathrm{Am}, \mathrm{Cm}$ and $\mathrm{Np}$ (approx. $1 \mathrm{wt} \%$ ) which are highly radiotoxic. The PUREX (Plutonium and URanium EXtraction) process using tributyl phosphate $\mathbf{1}$ (Figure 1) is currently used to separate the plutonium from the remaining waste enabling its recycling and reuse as MOX fuel in nuclear reactors. ${ }^{3}$ The remaining high level liquid waste (PUREX raffinate) still contains the minor actinides. The long-term radioactivity $\left(T_{1 / 2}=\right.$
$10^{3}-10^{4}$ years) of these elements presents a serious environmental and economic problem for the safe management and storage of the waste and necessitates that it be isolated from the biosphere for several thousands of years.

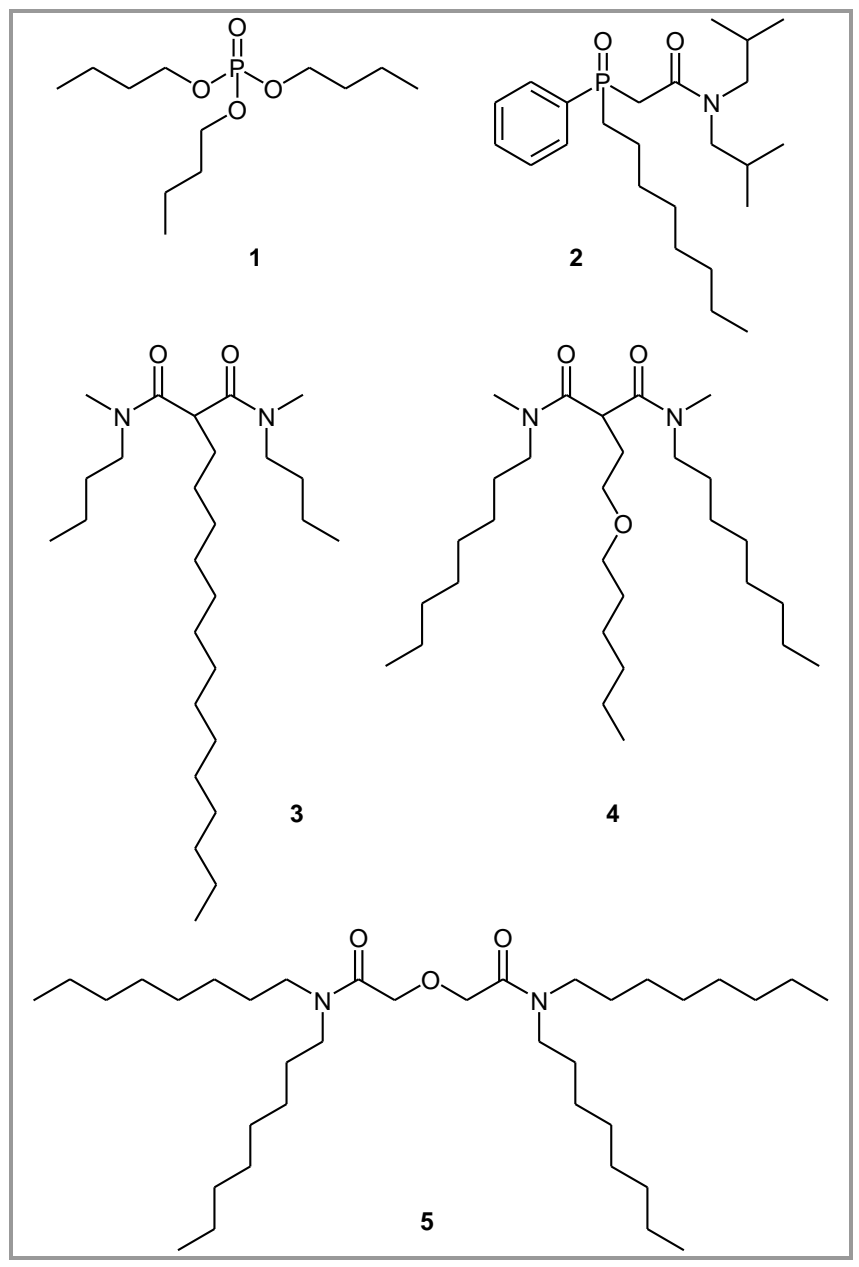

Figure 1 Structures of ligands used in the PUREX, TRUEX and DIAMEX processes

One possible strategy to reduce the radiotoxicity of the waste involves neutron bombardment (transmutation) of the minor actinides into shorterlived $\left(T_{1 / 2}=10^{1}\right.$ years $)$ or stable elements. ${ }^{4}$ However, the lanthanides have high neutron capture cross sections and absorb the neutrons in preference to the transmutable actinides. It is therefore necessary to first separate (partition) the actinides from the bulk of the 
lanthanides prior to their transmutation. This strategy, known as Partitioning and Transmutation, ${ }^{5}$ is a promising alternative to long term deep geological disposal of the high level waste.

In recent decades, there has been intensive research worldwide on the development of solvent extraction processes for the partitioning of actinides from lanthanides as part of a future strategy for the reprocessing of spent nuclear fuel. ${ }^{6}$ Within Europe, this research has led to the development of two proposed sequential processes. In the first process, both actinides and lanthanides are co-extracted from PUREX raffinate by a non-selective, diamide-based ligand. This is known as the DIAMEX (DIAMide EXtraction) process. ${ }^{7}$ In the second process, known as the SANEX (Selective ActiNide EXtraction) process, the minor actinides will be selectively extracted and separated from the lanthanides. Currently, the TRUEX (TRansUranium EXtraction) process, based on octyl(phenyl)- $N, N$ -

diisobutylcarbamoylmethylphosphine oxide (CMPO

2, Figure 1) as the principal extractant, is used in the United States ${ }^{8}$ to recover the actinides and lanthanides from high level waste solutions but no process is currently used worldwide for the actinide/lanthanide group separation.

Within the framework of several European Union funded research projects, a number of substituted diamide ligands have been developed for the DIAMEX process. ${ }^{9}$ Among these, $N, N$ '-dimethyl$N, N^{\prime}$-dibutyltetradecylmalonamide (DMDBTDMA) $\mathbf{3}^{10}$ and $N, N^{\prime}$-dimethyl- $N, N^{\prime}$ dioctlyhexoxyethylmalonamide (DMDOHEMA) $\mathbf{4}^{11}$ have shown the most promising results in extraction tests on genuine fuel solutions. More recently, $N, N, N$, $N$ '-tetraoctlydiglycolamide (TODGA) $\mathbf{5}$ (Figure 1) showed superior performance than 3 or 4 when tested on PUREX raffinate and this extractant is currently the preferred ligand for the DIAMEX process. ${ }^{12}$

For the SANEX process, the separation of actinides from lanthanides is much more challenging due to the chemically similar behavior of the two groups of elements (identical oxidation states, similar ionic radii due to lanthanide/actinide contractions). ${ }^{13}$ However, there is a more covalent contribution to metal-ligand bonding with the actinides than with the lanthanides. Consequently, ligands with softer donor atoms (eg: $\mathrm{N}$ and $\mathrm{S}$ ) than favour complexation with the $5 \mathrm{f}$ orbitals of the actinides have been the focus of research so as to exploit this difference between the coordination chemistries of the actinides and lanthanides. In the United States, the TALSPEAK process has been proposed to carry out this separation. ${ }^{14}$

Ligands suitable for the separation of actinides from lanthanides in a SANEX process must obey several important criteria. ${ }^{15}$ They should have a sufficiently high solubility in the organic diluent used for the extraction. The extracted species must also have good solubility in the organic phase to prevent third phase formation or precipitation. The ligand must show a high enough selectivity for the actinides so that the separation can be carried out in a relatively small number of extraction stages. It is also desirable that the affinity for the actinides is not so high that the back-extraction (stripping) of the metal from the extracted complexes and the subsequent recycling of the organic phase cannot take place. The ligand must show acceptable resistance towards both acidic hydrolysis and radiolysis, and any degradation products that form must not interfere with the extraction. The ligand should be able to extract from highly acidic (up to $4 \mathrm{M} \mathrm{HNO}_{3}$ ) solutions. It is also desirable that the ligand is composed of only $\mathrm{C}, \mathrm{H}, \mathrm{O}$ and $\mathrm{N}$ (CHON principle) so that the ligand or its degradation products can be completely incinerated at the end of its useful life, thereby avoiding secondary waste generation. Finally, the ligand must be as cheap and easy to synthesize as possible so that large-scale commercial production is feasible.

In solvent extraction experiments, ${ }^{241} \mathrm{Am}(\mathrm{III})$ and ${ }^{152} \mathrm{Eu}(\mathrm{III})$ radioisotopes are typically used as representatives for the actinides and lanthanides, respectively. The effectiveness of a ligand in extracting a metal $\mathrm{M}$ is quantified by the distribution ratio $\left(D_{\mathrm{M}}\right)$, which is the equilibrium ratio between the metal concentration in the organic and in the aqueous phase. The separation factor for Am over $\mathrm{Eu}\left(\mathrm{SF}_{\mathrm{Am} / \mathrm{Eu}}\right)$ is the ratio of the $D$ values for Am and Eu and is thus a measure of the selectivity of a ligand for the actinides over the lanthanides. Thus the optimum ligand will have $D_{\mathrm{Am}}>1$ and $\mathrm{SF}_{\mathrm{Am} / \mathrm{Eu}}$ as large as possible.

A large number of potential SANEX ligands has been developed in recent decades. ${ }^{16}$ In this account, we review the $\mathrm{N}$ - and $\mathrm{S}$-donor ligands for the SANEX process that have been developed within the framework of several European Union funded research programmes that show the most promising properties for actinide/lanthanide separations. The harder O-donor ligands, which are generally nonselective, are thus out of the scope of this review.

\section{Dithiophosphinic Acids}

The bidentate, S-donor dithiophosphinic acids were one of the first classes of reagent to show very high selectivities for An(III) over Ln(III). Dithiophosphinic acids studied for their ability to separate An from Ln are shown in Table 1. It was shown in early studies by Zhu that Cyanex 301, a commercial reagent composed mainly $\quad\left(\begin{array}{lll}\sim & 80 & \%\end{array}\right)$ of $\operatorname{bis}(2,4,4-$ trimethylpentyl)dithiophosphinic acid 6, efficiently separated Am(III) from Ln(III) with very high selectivities. The selectivity of the extraction increased when the reagent was fully purified $\left(\mathrm{SF}_{\mathrm{Am} / \mathrm{Eu}}\right.$ $>$ 4000, average $\left.\mathrm{SF}_{\mathrm{Am} / \mathrm{Ln}}>2300\right){ }^{17}$ Both the 
Table 1 Dithiophosphinic acids studied for their ability to extract and separate An(III) from Ln(III)

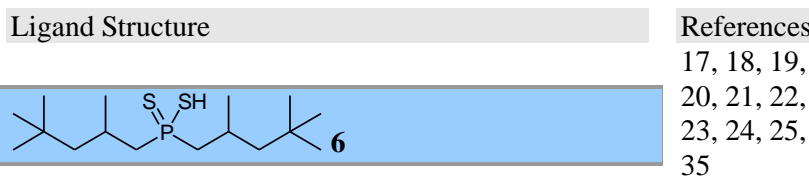

33

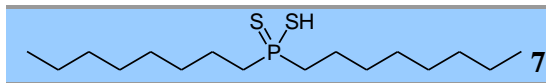

33

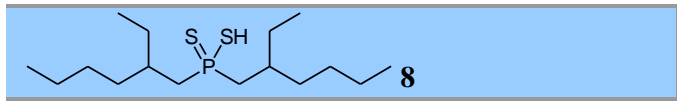

33

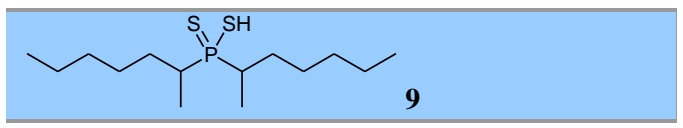

33

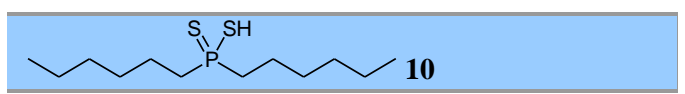

33

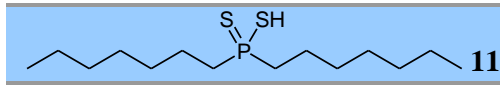

11

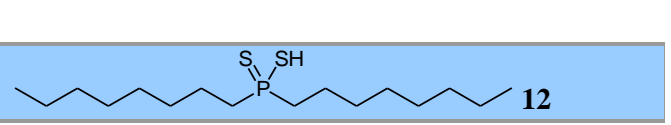

33

33

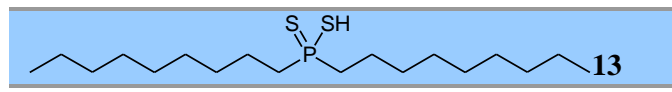

33

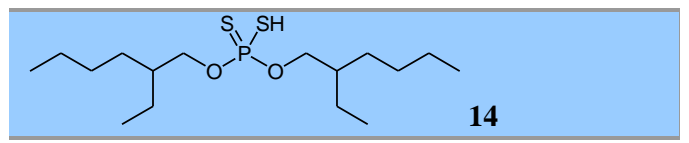

26a, 26b, 27,

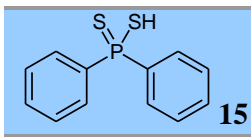

33,35

extraction efficiency and selectivity were enhanced in formed mixed metal complexes with $\mathbf{6}^{18}$ In synergistic combination with the softer $\mathrm{N}$-donor ligands 2,2'-bipyridine and 1,10-phenanthroline, the selectivity was further enhanced resulting in one of

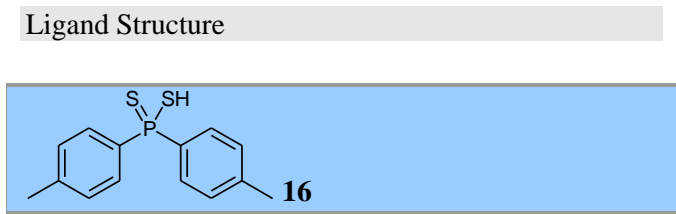

References $26 \mathrm{~b}, 27,33$

$26,27,28$,

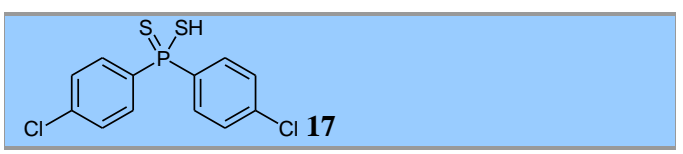

$29,30,31$

33,34

26a, 27
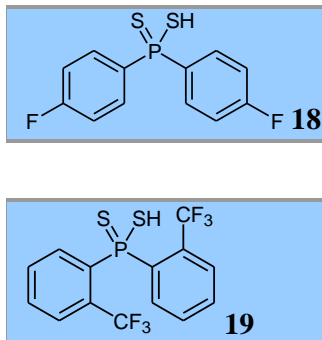

32

$32 b$

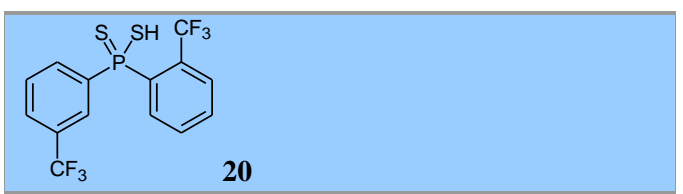

$32 b$
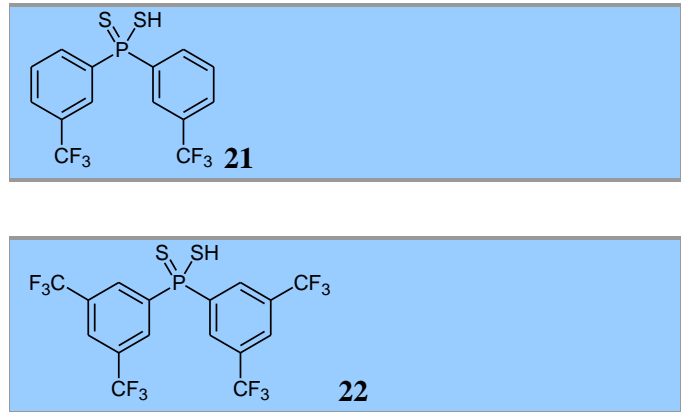

$32 \mathrm{a}$

33

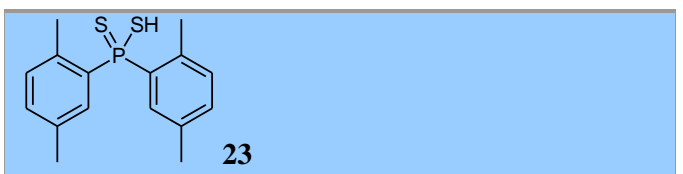

33

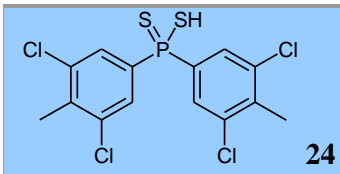

24

33

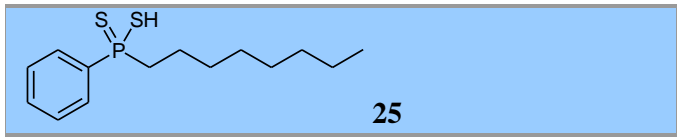

the presence of several O-donor synergists which the highest reported separation factors to date $\left(\mathrm{SF}_{\mathrm{Am} / \mathrm{Eu}}\right.$ $>$ 40000). ${ }^{19}$

Promising results were also observed in the extraction 
of $\mathrm{An}$ (III) and $\mathrm{Ln}$ (III) from acetic acid/ammonium acetate buffered solutions that would result from a preceeding TRUEX separation step. ${ }^{20}$ In addition, the successful separation of $\mathrm{An}(\mathrm{III})$ from $\mathrm{Ln}(\mathrm{III})$ by purified bis(2,4,4-trimethylpentyl)dithiophosphinic acid 6 immobilized on silica resins, ${ }^{21}$ or enclosed in biopolymer microcapsules ${ }^{22}$ or in supported liquid membranes, ${ }^{23}$ has been demonstrated. In a laboratoryscale countercurrent extraction test, $>99.998 \%$ of Am(III) was extracted and separated from macroamounts of $\operatorname{Ln}(\mathrm{III})$ using purified $\mathbf{6}$ and tributyl phosphate. ${ }^{24}$ Unfortunately, 6 can only extract from nitric acid solutions of relatively low acidity $(\mathrm{pH}>$ 2.5) due to non-dissociation/oxidative degradation of the extractant at low $\mathrm{pH}$. Furthermore, $\mathbf{6}$ was found to decompose to its corresponding monothiophosphinic acid and phosphinic acids on exposure to $700 \mathrm{Kgy}$ of $\gamma$-radiation, with deleterious effects on the extraction performance and selectivity. ${ }^{25}$

To address these shortcomings, a series of more acidic aromatic dithiophosphinic acids was developed by Modolo. Compounds 15-18 were synthesized by treatment of phosphorus pentasulfide with aluminum chloride in the presence of an aromatic hydrocarbon (Scheme 1). The ligands efficiently extracted Am(III) and $\mathrm{Eu}(\mathrm{III})$ into toluene from $0.1-1 \mathrm{M} \mathrm{HNO}_{3}$ in synergistic combination with tributyl phosphate or a trialkylphosphine oxide, with the best results being observed for bis(chlorophenyl)dithiophosphinic acid $17 .^{26}$ No extraction occurred by the ligands alone in the absence of a synergist. The dependence of the distribution ratios for An(III) on extractant concentration indicate that the dithiophosphinic acids extract An(III) as 1:3 complexes. The aromatic dithiophosphinic acids were also more resistant to radiolysis than Cyanex 3016 . Only minor $(<5 \%)$ decomposition was observed after exposure to 1000 KGy of $\gamma$-radiation, whereas $>80 \%$ decomposition of Cyanex 3016 occurred under the same conditions. ${ }^{27}$ However, complete oxidative degradation of the ligands occurred in contact with strongly acidic (> 2 M) nitric acid solution over 100 days. ${ }^{28}$

The synergistic mixture of bis(chlorophenyl)dithiophosphinic acid $\mathbf{1 7}$ and tris(2ethylhexyl)phosphate extracted $\mathrm{Am}(\mathrm{III})$ and $\mathrm{Cm}(\mathrm{III})$ from the lanthanides with very high separation factors $\left(\mathrm{SF}_{\mathrm{Am} / \mathrm{Ln}}>\right.$ 3000). More surprisingly, an $\mathrm{Am}(\mathrm{III}) / \mathrm{Cm}$ (III) separation factor $>8$ was observed, suggesting that the system could be used for the challenging separation of $\mathrm{Am}(\mathrm{III})$ from $\mathrm{Cm}(\mathrm{III}) .{ }^{29} \mathrm{In}$ a subsequent laboratory-scale separation process using centrifugal contactors, this synergistic combination selectively extracted $99.8 \%$ Am(III) from a mixture of $\mathrm{Am}(\mathrm{III}), \mathrm{Cm}(\mathrm{III}), \mathrm{Cf}(\mathrm{III})$ and $\mathrm{Eu}(\mathrm{III})$, with only $0.47 \% \mathrm{Cm}(\mathrm{III})$ being extracted into the organic phase. $^{30}$

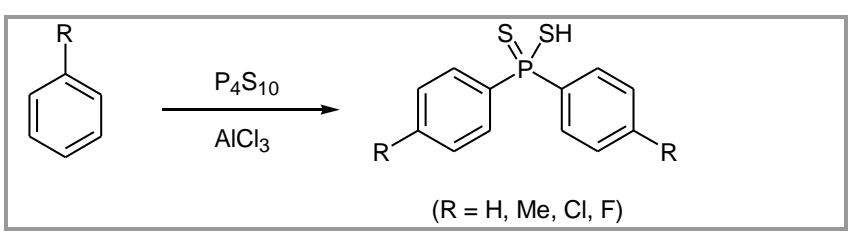

Scheme 1 Synthesis of aromatic dithiophosphinic acids

It has been shown that a donor-acceptor mechanism of extraction operates to promote the extraction of Am(III) by synergistic mixtures of dithiophosphinic acids and neutral O-donor ligands. ${ }^{31}$ Strong O-donor ligands such as trialkylphosphine oxides tend to strengthen $\mathrm{M}-\mathrm{S}$ bonds and increase $D_{\mathrm{Am}}$, whereas weaker O-donor ligands such as triaryl phosphates tend to weaken $\mathrm{M}-\mathrm{S}$ bonds and decrease $D_{\mathrm{Am}}$. For those synergists giving high $\mathrm{Am} / \mathrm{Eu}$ separation factors (trialkyl phosphates), an antagonistic effect was observed for $\mathrm{Eu}(\mathrm{III})$ complex formation but not for Am(III) complex formation.

Recently, bis(trifluoromethylphenyl)dithiophosphinic acids 19, 20 and 21 were synthesized regioselectively by a multi-step route and evaluated in Am(III) and $\mathrm{Eu}(\mathrm{III})$ solvent extraction experiments to determine the effect of the location of the trifluoromethyl-group on the extraction properties. ${ }^{32}$ The ortho-substituted ligands 19 and 20 showed unprecedented selectivity for $\mathrm{Am}(\mathrm{III})$ over $\mathrm{Eu}(\mathrm{III})\left(\mathrm{SF}_{\mathrm{Am} / \mathrm{Eu}}>100,000\right)$ but the meta-disubstituted ligand $\mathbf{2 1}$ was far less selective $\left(\mathrm{SF}_{\mathrm{Am} / \mathrm{Eu}} \sim 20\right)$, demonstrating that the location of the substituent played a key role in the extraction selectivity. In a related study on several alkyl and arylsubstituted dithiophosphinic acids, the presence of electron-withdrawing groups on the aromatic rings in the aryl-substituted ligands increased the selectivity, but decreased the extraction ability. ${ }^{33}$ For the alkylsubstituted ligands, branched alkyl chains increased the selectivity.

The origin of the high selectivity of synergistic mixtures of bis(chlorophenyl)dithiophosphinic acid $\mathbf{1 7}$ and neutral O-donor ligands for An(III) over Ln(III) was established by EXAFS and time-resolved laser fluorescence spectroscopy (TRLFS). ${ }^{34}$ The structures of the inner coordination spheres of the $\mathrm{Cm}$ (III) and $\mathrm{Eu}(\mathrm{III})$ complexes were different. While $\mathrm{Cm}$ (III) primarily bound to the $\mathrm{S}$-atoms of the ligand in a bidentate fashion, Eu(III) preferentially bound the Oatoms of the synergist, suggesting that a high number of covalent M-S bonds is responsible for the high selectivity. The primary role of the synergist appears to be co-complexation of the metal ions to form more hydrophobic complexes. Molecular dynamics simulations show that the ligands and their Eu(III) complexes are surface active, but synergists like tributyl phosphate also promote the extraction to the organic phase by aggregating at the interface where they lower its surface tension and promote the transfer of the complexes into the organic phase. ${ }^{35}$ 


\section{TERPY and Related Ligands}

The tridentate aromatic nitrogen donor ligand 2,2':6',2"'-terpyridine 26 (TERPY) was one of the first $\mathrm{N}$-donor ligands investigated for its ability to selectively extract Am(III) from Eu(III). A list of TERPY and its derivatives tested for their ability to separate Am(III) from Eu(III) is shown in Table 2. In synergistic combination with 2-bromodecanoic acid (which acts as a lipophilic anion source), TERPY selectively extracted Am(III) from weakly acidic aqueous solutions up to $0.1 \mathrm{M} \mathrm{HNO}_{3}$ into THP (hydrogenated tetrapropene) with $\mathrm{SF}_{\mathrm{Am} / \mathrm{Eu}}$ of $7.2 .^{36,37}$ However, the $D$ value for Am(III) progressively decreased at higher acidities $\left(\left[\mathrm{HNO}_{3}\right]>0.1\right)$ due to protonation and subsequent dissolution of the ligand in the aqueous phase. No significant extraction of Am(III) or Eu(III) was observed by TERPY alone.

The more hydrophobic derivatives 4'-octyl$2,2^{\prime}: 6$ ',2"'terpyridine 27 and 4,4',4"'tri-tert-butyl2,2':6',2"'-terpyridine $\mathbf{2 8}$ (Table 2) were then investigated. However, at comparable acidities the $D$ values for Am(III) were substantially lower than for TERPY 26. ${ }^{36}$ Although alkyl substitution was expected to increase the $D$ values by improving the solubility of the extracted complex in the organic phase, it appeared to increase the basicity of the ligand so that protonation of the donor atoms competed effectively with metal ligation. Similar results were observed with phenyl-substituted derivatives 29, 30 and 32, and pyrazine derivative $31 .^{38}$ All of the substituted ligands became protonated at higher acid concentrations and precipitation of the protonated ligands was observed in some cases.

In an effort to better understand the types of species which may be involved in the extraction, a series of complexes formed by TERPY $\mathbf{2 6}$ and the lanthanides were synthesized and structurally characterized. ${ }^{38,39}$ In most cases, neutral 1:1 species $\left[\mathrm{M}(\mathrm{L})\left(\mathrm{NO}_{3}\right)_{3}\right](\mathrm{L}=$ TERPY) were observed although with $\mathrm{Nd}, \mathrm{Sm}, \mathrm{Tb}$, Dy and Ho, complex ion-pairs composed of $\left[\mathrm{M}(\mathrm{L})_{2}\left(\mathrm{NO}_{3}\right)_{2}\right]^{+}$cations and $\left[\mathrm{M}(\mathrm{L})\left(\mathrm{NO}_{3}\right)_{4}\right]^{-}$anions were observed. However, under anhydrous conditions 1:2 complexes of formula $\left[\mathrm{MI}_{2}(\mathrm{TERPY})_{2}\right] \mathrm{I}$ were formed between TERPY and $\mathrm{MI}_{3}(\mathrm{M}=\mathrm{Ce}, \mathrm{Nd}, \mathrm{U}){ }^{40}$ $\mathrm{X}$-ray crystallographic analysis revealed shorter average $\mathrm{M}-\mathrm{N}$ distances in the $\mathrm{U}$ complex than the $\mathrm{Ce}$ complex, suggesting a possible $\pi$-backbonding interaction and thus greater covalency in the U(III) complex.
Table 2 TERPY and related ligands studied for their ability to extract and separate An(III) from $\mathrm{Ln}$ (III)

Ligand Structure

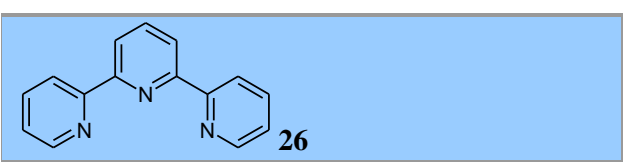

\section{References} 36, 37, 38, $39,40,41$, 46, 73b, 76b $78,109 \mathrm{~b}$

36

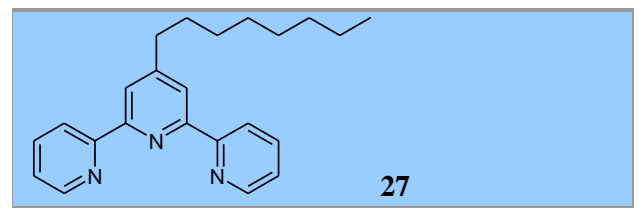

36

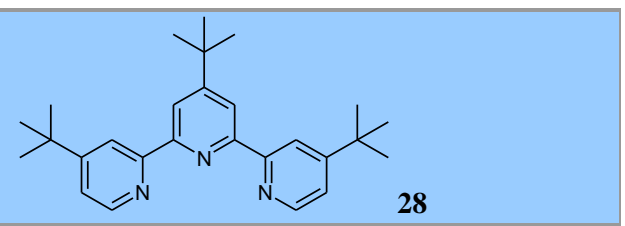

38

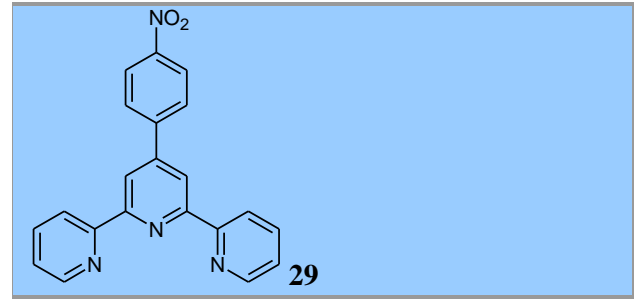

38

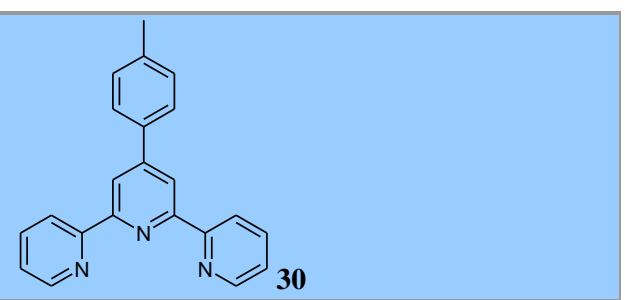

38

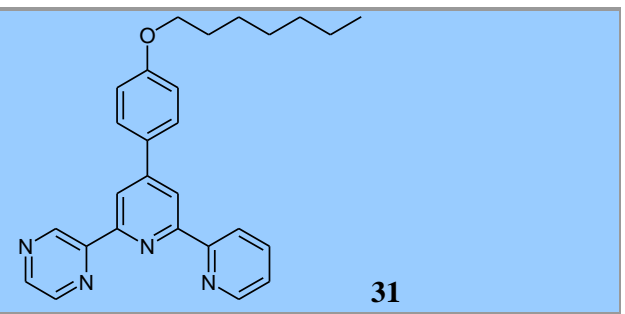

38

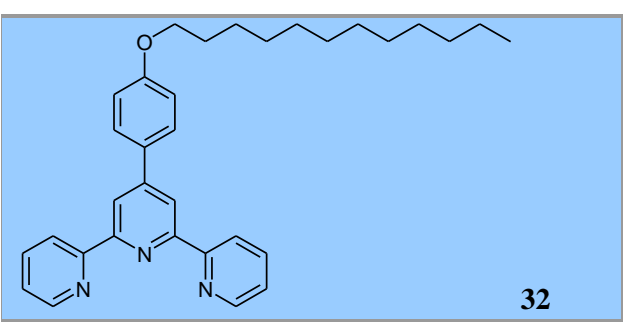

The structures of the mono- and diprotonated TERPY cations were determined by $A b$ initio quantum 
mechanics calculations and by X-ray crystallographic analysis of the ion pairs formed between the diprotonated TERPY cation and nitratolanthanate $\left(\left[\mathrm{M}\left(\mathrm{NO}_{3}\right)_{5}\right]^{2-}\right)$ anions of $\mathrm{La}$ and $\mathrm{Sm} .^{41}$ The isolation of these species in the solid state suggests that TERPY and its derivatives could extract the metals by an ionpair mechanism as well as by simple solvation, particularly at high acidities.

\section{TPTZ and Related Ligands}

The tridentate N-donor ligand 2,4,6-tri-(2-pyridyl)1,3,5-triazine (TPTZ) and its derivatives are synthesized by cyclotrimerization of 2-cyanopyridines under acidic, basic or neutral conditions (Scheme 2). ${ }^{42}$ 2,4,6-tri-(2-pyridyl)-1,3,5-triazine and related ligands that were tested for their ability to separate Am(III) from $\mathrm{Eu}(\mathrm{III})$ are shown in Table 3. It was reasoned that replacing the central pyridine ring of TERPY with a 1,3,5-triazine ring would reduce the basicity of the ligand and therefore lower the solubility of the protonated ligand in the aqueous phase at low $\mathrm{pH}$.

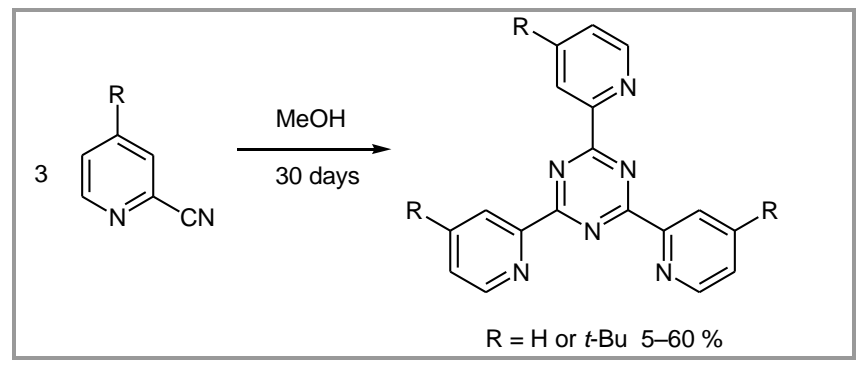

Scheme 2 Synthesis of 2,4,6-tri-(2-pyridyl)-1,3,5-triazine ligands

In solvent extraction experiments, TPTZ 33 performed slightly better than TERPY $\mathbf{2 6}$ and higher $D$ values were observed for Am(III) when used in combination with 2-bromodecanoic acid in TPH. TPTZ was also the first $\mathrm{N}$-donor ligand to show $\mathrm{SF}_{\mathrm{Am} / \mathrm{Eu}}>10$. In contrast to the more lipophilic derivatives of TERPY, the extraction was further improved in the more lipophilic TPTZ derivative $\mathbf{3 4}$ which gave slightly higher $D_{\mathrm{Am}}$ values than TPTZ and $\mathrm{SF}_{\mathrm{Am} / \mathrm{Eu}}=11.9$. $^{36}$ Once again however, the ligands were incapable of extracting the metals from solutions more acidic than $0.1 \mathrm{M} \mathrm{HNO}_{3}$. X-ray crystallographic structures of the 1:1 complexes formed between $\mathrm{Ce}(\mathrm{IV})$ and $\mathrm{Sm}(\mathrm{III})$ nitrates and 2,4,6-tri-(4-tert-butyl-2-pyridyl)-1,3,5triazine 34, and complexes in which the protonated ligand forms salts with a variety of anions have been obtained, illustrating the versatile coordination chemistry of this class of ligand. ${ }^{43}$ For TPTZ 33, both 1:1 and 1:2 complexes with the trivalent lanthanides and actinides have been observed under different conditions. ${ }^{44}$
Table 3 TPTZ and related ligands studied for their ability to extract and separate $\mathrm{An}(\mathrm{III})$ from $\mathrm{Ln}$ (III)

Ligand Structure

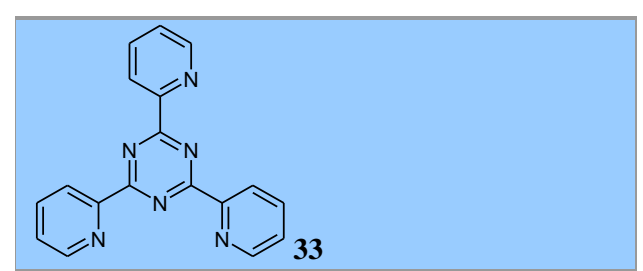

References

$36,37,42 \mathrm{~b}$,

$42 \mathrm{c}, 42 \mathrm{~d}$,

$43 \mathrm{~b}, 76 \mathrm{~b}, 78$,

108

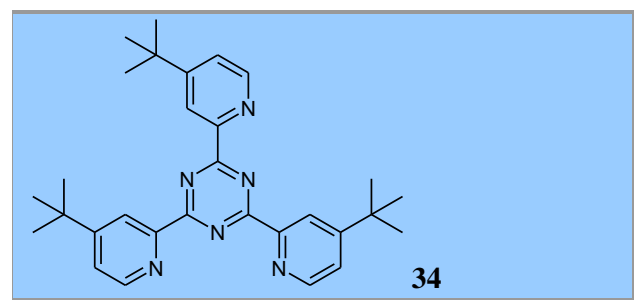

$36,42 \mathrm{c}, 43 \mathrm{a}$

46

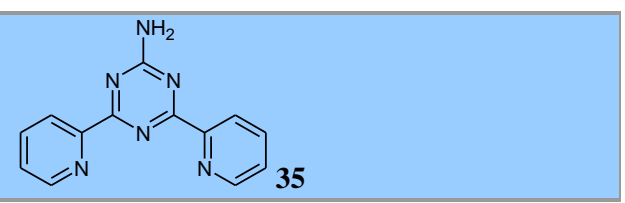

$45,46,47$

$76 \mathrm{~b}, 78$

46

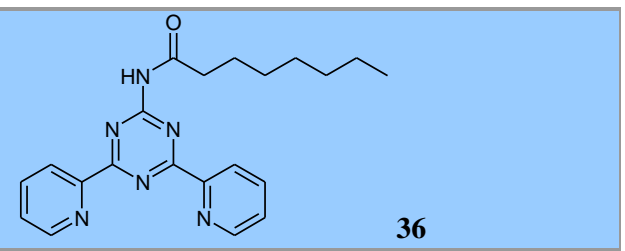

46

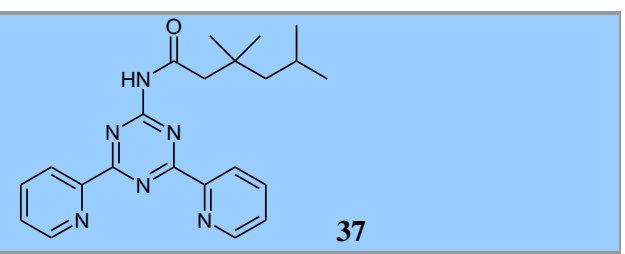

46

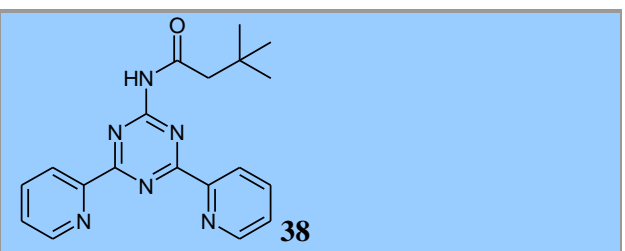

46

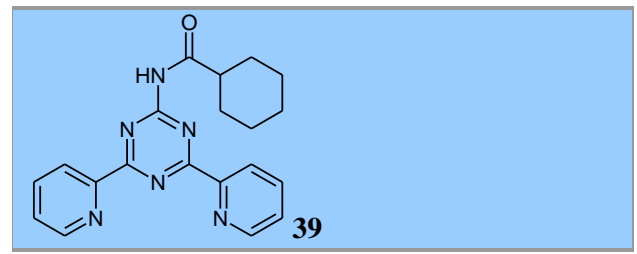

The promising results obtained with TPTZ and its derivatives led us to investigate the related ligand 4amino-2,6-bis(2-pyridyl)-1,3,5-triazine 35 (ADPTZ) that features the same tridentate coordination cavity as 
TPTZ, but is more easily functionalized to obtain more hydrophobic derivatives. This and related ligands are synthesized by treatment of a 2cyanopyridine with guanidine in ethanolic sodium ethoxide (Scheme 3). ${ }^{42 a}$ The coordination chemistry of 35 with the trivalent lanthanides has been investigated. ${ }^{45}$ X-ray crystallographic analysis revealed the formation of five structural types. In each case, the tridentate ligand formed 1:1 complexes and the remainder of the metals inner coordination sphere was occupied by a combination of water molecules and nitrate ions. The structures appeared to be stabilized by intermolecular hydrogen bonding involving the free amino-group.

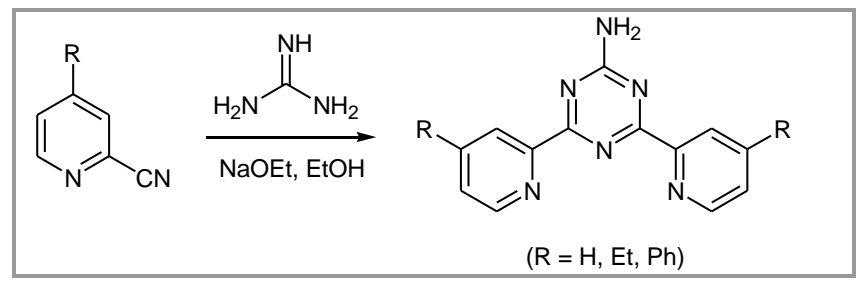

Scheme 3 Synthesis of 4-amino-2,6-bis(2-pyridyl)-1,3,5-triazine ligands

In $\mathrm{Am}(\mathrm{III}) / \mathrm{Eu}(\mathrm{III})$ solvent extraction experiments, 35 and its hydrophobic amido-derivatives 36-39 (Table 3) gave results comparable to TPTZ $\mathbf{3 3}$ and $\mathbf{3 4} .^{46}$ Although relatively high $D$ values for Am(III) were obtained in synergy with 2-bromodecanoic acid (eg: $D_{\mathrm{Am}}=45$; organic phase $=0.02 \mathrm{M} \mathrm{35}$ and $1 \mathrm{M} \mathrm{2-}$ bromodecanoic acid in TPH; aqueous phase $=0.03 \mathrm{M}$ $\mathrm{HNO}_{3}$ with $\mathrm{Am}(\mathrm{III})$ and $\mathrm{Eu}(\mathrm{III})$ tracers), these values decreased rapidly as the concentration of nitric acid increased. Am(III) distribution ratios less than 1 were observed when $\left[\mathrm{HNO}_{3}\right] \geq 0.1 \mathrm{M}$. The selectivity $\left(\mathrm{SF}_{\mathrm{Am} / \mathrm{Eu}}\right)$ ranged between 6.5 and 12 .

The amido-derivatives 36-39 showed identical coordination chemistry towards the lanthanides as the parent compound 35, and crystallographic structures of the 1:1 complexes with $\mathrm{Yb}(\mathrm{III})$ have been obtained. $^{46}$ Complexation and microcalorimetry studies in $\mathrm{H}_{2} \mathrm{O} / \mathrm{MeOH}$ showed that the $\mathrm{Am}(\mathrm{III})$ complex of ADPTZ 35 was more stable than the lanthanide complexes by a factor of about 20 , and is driven primarily by a more exothermic enthalpy of complex formation. ${ }^{47}$ This supports the view that the preference of the ligand for An(III) is due to a greater degree of covalency in the $\mathrm{M}-\mathrm{L}$ bonds than with Ln(III).

\section{BODO and Related Ligands}

In searching for a new class of weakly basic ligand that could also separate An(III) from $\operatorname{Ln}$ (III), our attention was drawn to ligands related to 2,6bis(benzimidazol-2-yl)pyridine whose synthesis takes place in polyphosphoric acid at $200-230{ }^{\circ} \mathrm{C} .{ }^{48}$ This stability towards strongly acidic conditions at high temperatures would be very desirable in a future separation process. In addition, ligands based on the related 2,6-bis(benzoxazol-2-yl)pyridine and 2,6bis(benzothiazol-2-yl)pyridine would be expected to be less basic, as both benzoxazole and benzothiazole have $\mathrm{pKa}$ values lower than benzimidazole. A typical procedure for the synthesis of 2,6-bis(benzoxazol-2yl)pyridines is shown in Scheme 4. Thus a range of hydrophobic tridentate pyridine ligands containing benzimidazole, benzoxazole and benzothiazole rings (see Table 4) were synthesized and assessed for their ability to extract and separate $\mathrm{An}(\mathrm{III})$ from $\mathrm{Ln}(\mathrm{III}){ }^{49}$

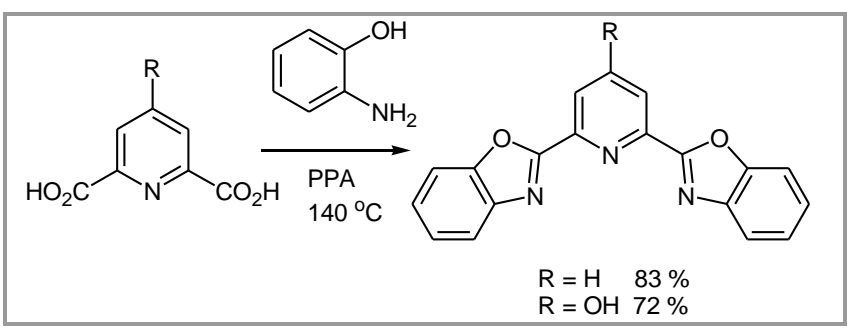

Scheme 4 Synthesis of bis(benzoxazol-2-yl)pyridine ligands

The most promising results were obtained with 2,6bis(benzoxazol-2-yl)-4-dodecyloxypyridine (BODO) 42 and its branched derivative $\mathbf{4 3}$ in combination with 2-bromodecanoic acid as a synergist. Relatively high separation factors were observed $\left(\mathrm{SF}_{\mathrm{Am} / \mathrm{Eu}} 36-79\right.$ for 42, $\mathrm{SF}_{\mathrm{Am} / \mathrm{Eu}} 43-70$ for 43) and these values actually increased at higher acidities (up to $0.1 \mathrm{M} \mathrm{HNO}_{3}$ ). This was the first time that an increase in $\mathrm{SF}_{\mathrm{Am} / \mathrm{Eu}}$ had been observed with increasing $\left[\mathrm{HNO}_{3}\right]$ for an $\mathrm{N}$-donor ligand. The $D$ values for Am(III) were greater for the branched ligand $\mathbf{4 3}$ than for $\mathbf{4 2}$ but once again these values decreased as $\left[\mathrm{HNO}_{3}\right]$ increased, and no significant extraction occurred at higher acidities. Xray crystallographic studies with 2,6-bis(benzoxazol2-yl)pyridine $\mathbf{4 0}$ showed that, as with other terdentate ligands based on TERPY and TPTZ, only 1:1 complex formation occurred with the trivalent lanthanide nitrates. ${ }^{49}$

In further solvent extraction experiments with BODO, it was found that at constant acidity, both $D_{\mathrm{Am}}$ and $\mathrm{SF}_{\mathrm{Am} / \mathrm{Eu}}$ decreased as either $\left[\mathrm{NO}_{3}{ }^{-}\right]$or $\left[\mathrm{ClO}_{4}{ }^{-}\right]$ increased. ${ }^{50}$ In addition, the ligand was not extracted into the aqueous phase when contacted with $2 \mathrm{M}$ or 4 $\mathrm{M} \mathrm{HNO}$ solutions and could be recovered from the organic phase, demonstrating its resistance to protonation. The decrease in $D_{\mathrm{Am}}$ and $\mathrm{Am} / \mathrm{Eu}$ selectivity as the nitrate concentration increases is most likely due to the inability of BODO to compete with nitrate ions which must be displaced from the metal by the ligand so that a hydrophobic extractable complex can form. 
Table 4 BODO and related ligands studied for their ability to extract and separate An(III) from Ln(III)

Ligand Structure

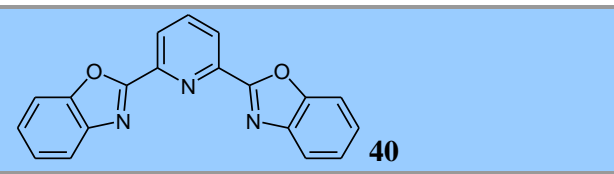

49

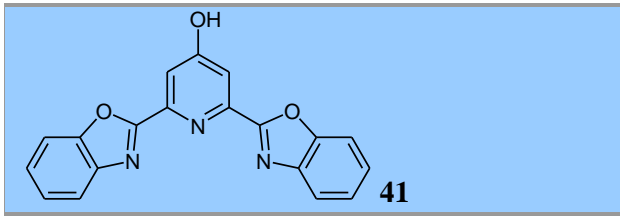

49,50

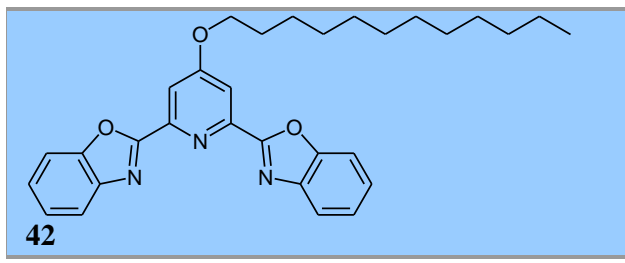

49

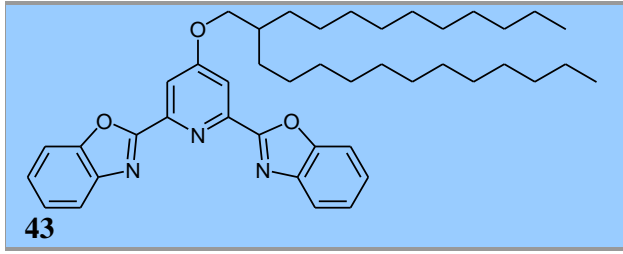

49

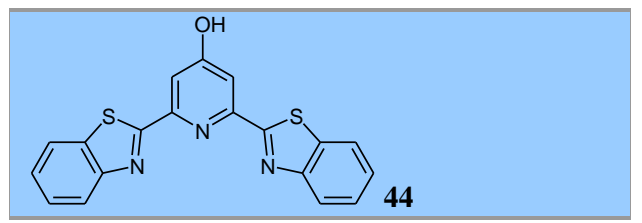

49

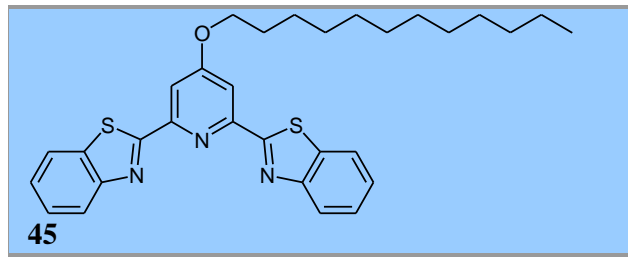

49,78

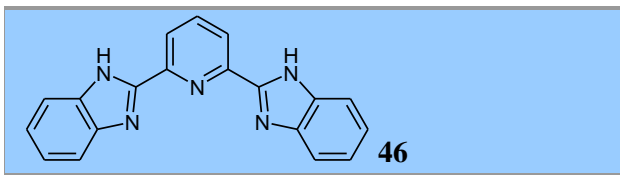

49

References

49
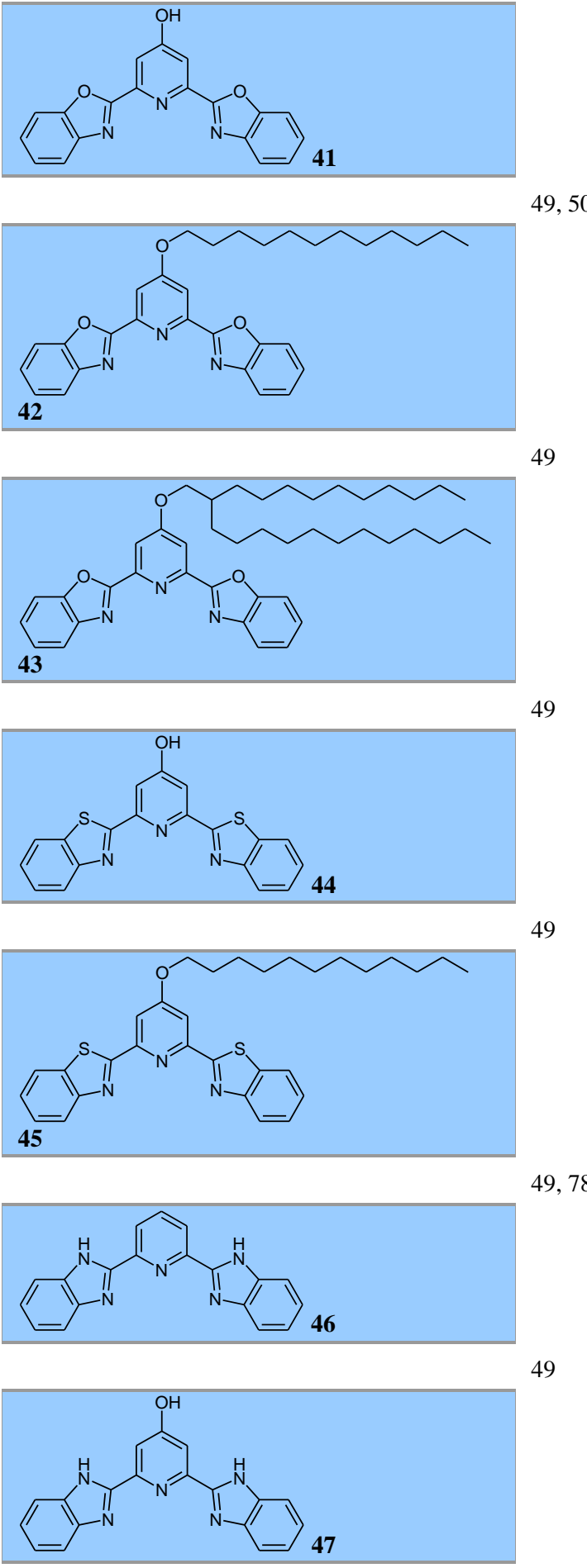

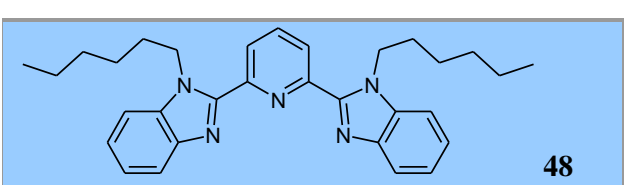

49

49

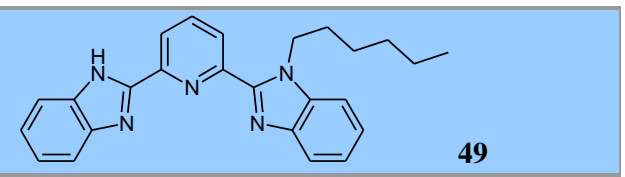

49

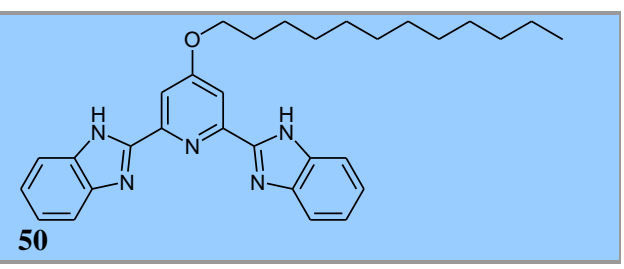

\section{Podant Ligands}

Encapsulating podant ligands are well known in coordination chemistry, and a series of polydentate podant $\mathrm{N}$-donor ligands have been investigated for their ability to separate An(III) from Ln(III). The ligands investigated are presented in Table 5, and are based on the tripodal ligands tris[(2pyridyl)methyl]amine and tris(2-pyridyl)methanol, and the tetrapodal ligand $N, N, N^{\prime}, N^{\prime}$-tetrakis[(2pyridyl)methyl]-ethylenediamine (TPEN).

In solvent extraction experiments, tris[(2pyridyl)methyl]amine $\mathbf{5 1}(1 \mathrm{mM}$ in TPH) only weakly extracted Am(III) from nitric acid solutions $\left(D_{\mathrm{Am}} \sim\right.$ 0.25 from ca. $0.01 \mathrm{M} \mathrm{HNO}_{3}$ ) with low selectivity $\left(\mathrm{SF}_{\mathrm{Am} / \mathrm{Eu}}<2\right)$ in the presence of the synergist 2bromodecanoic acid. ${ }^{51}$ The results with the softer, more soluble ligand tris[(2-pyrazinyl)methyl]amine $\mathbf{5 2}$ were more promising $\left(D_{\mathrm{Am}}=4.6, \mathrm{SF}_{\mathrm{Am} / \mathrm{Eu}}=10.8\right.$ for $20 \mathrm{mM} 52$ in TPH) but no extraction occurred from more acidic solutions $(\mathrm{pH} \leq 1)$ due to protonation of the ligands. More recently, chiral tris[(2pyridyl)methyl]amine ligands 54, 55 and 56 exhibited improved extraction performance at $\mathrm{pH}>4.7$ in nitrobenzene in the presence of 2-bromodecanoic acid. $^{52}$ The best results were obtained with the monomethyl compound $(R)-\mathbf{5 4}\left(D_{\mathrm{Am}}=52.3, \mathrm{SF}_{\mathrm{Am} / \mathrm{Eu}} \sim\right.$ $10)$ and the dimethyl compound $(R, S)-\mathbf{5 6}\left(D_{\mathrm{Am}}=26.8\right.$, $\left.\mathrm{SF}_{\mathrm{Am} / \mathrm{Eu}}>25\right)$.

A series of $1: 1$ complexes of tris[(2pyridyl)methyl]amine $\mathbf{5 1}$ and tris[(2pyrazinyl)methyl]amine $\mathbf{5 2}$ with the lanthanides have been isolated and characterized by X-ray crystallography. ${ }^{51}$ The structures show the ligand coordinates in a tetradentate capping mode with participation of the central podant $\mathrm{N}$ atom. A similar 1:1 complex was formed between tris[(2- 
Table 5 Podant ligands studied for their ability to extract and separate An(III) from Ln(III)

Ligand Structure
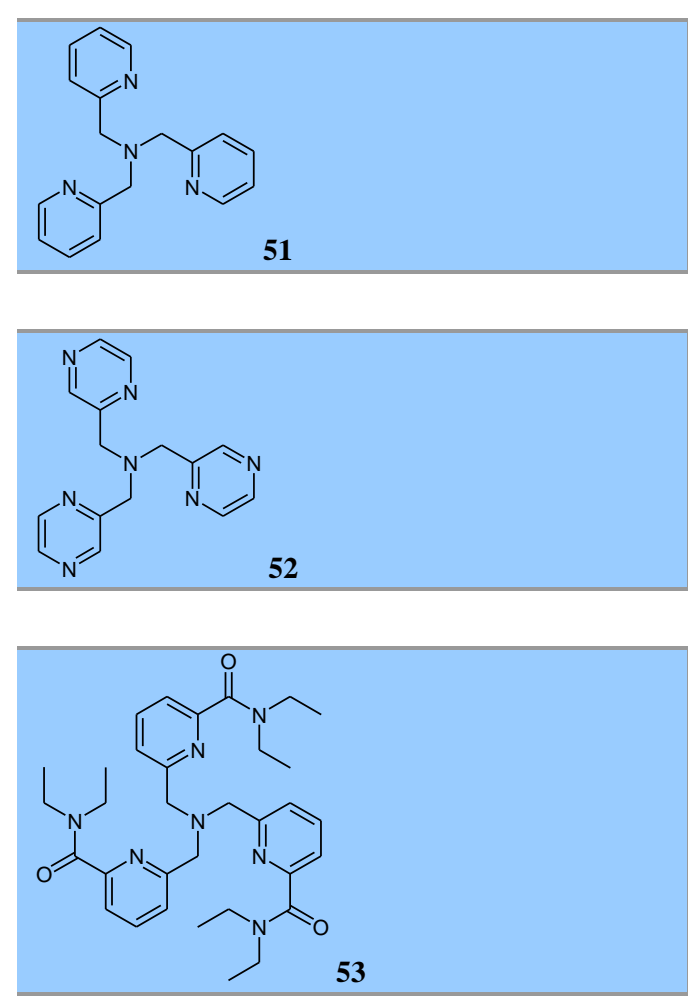

52

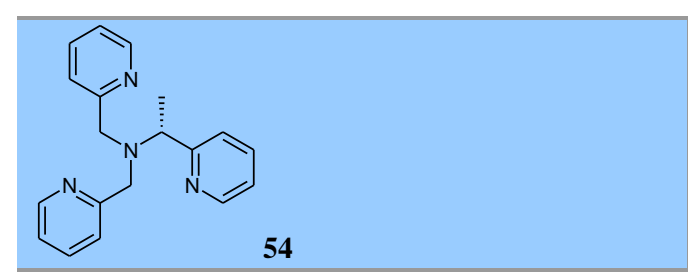

52

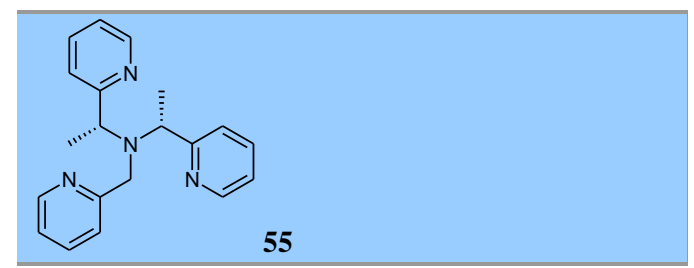

52

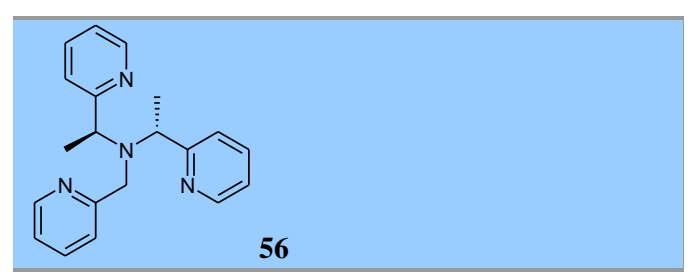

55

55
References

51, 53, 54,

$51,56,59$
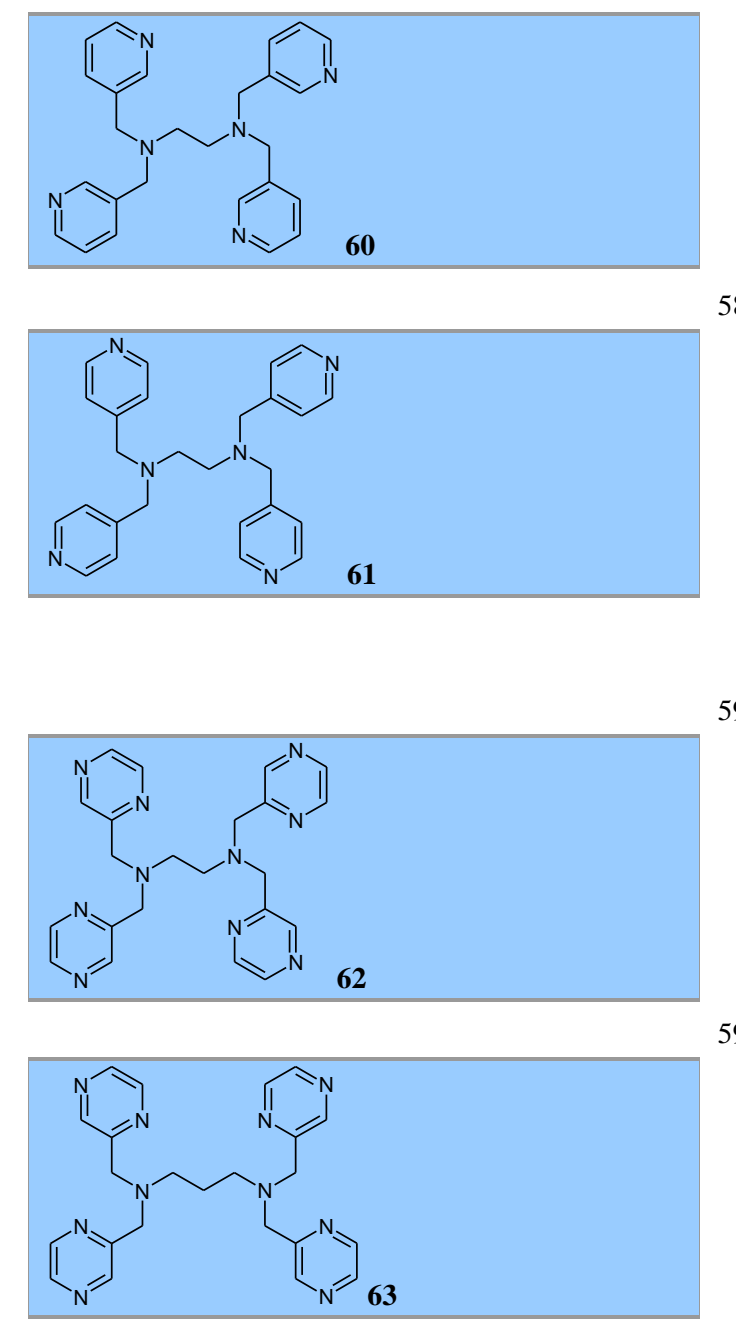

59

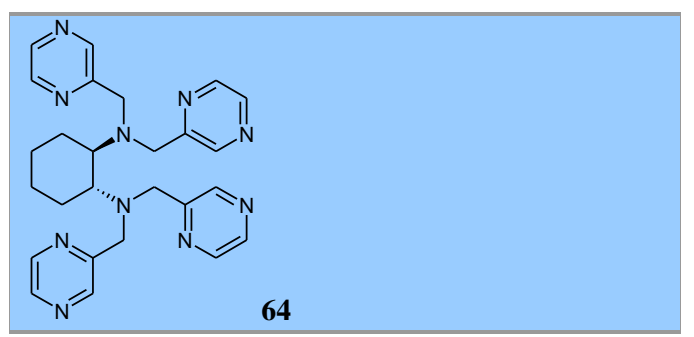

58

59

References

57, 58

58

59 


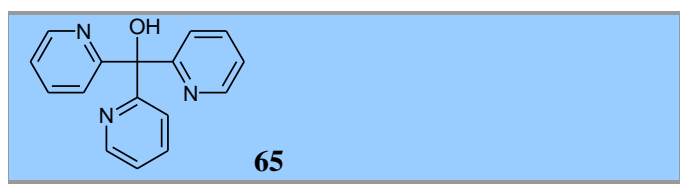

$60 \mathrm{a}, 61,62$

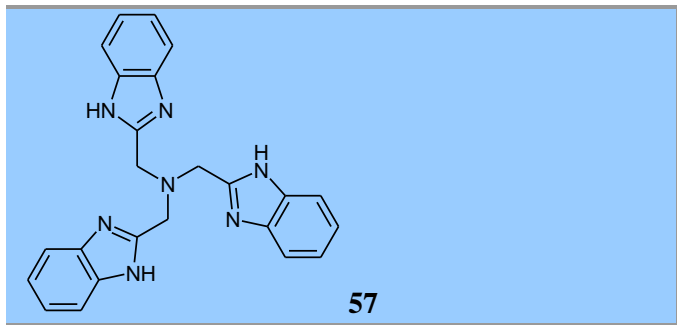

53

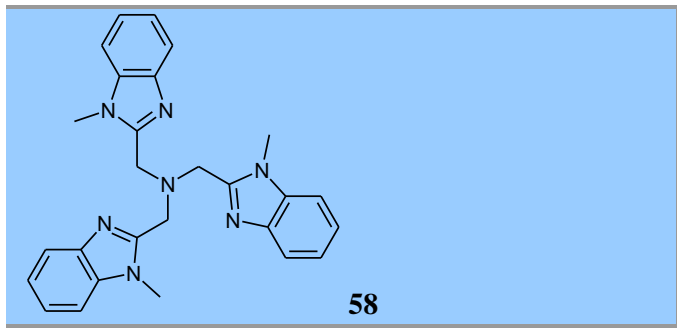

pyridyl)methyl]amine $\mathbf{5 1}$ and $\left[\mathrm{UI}_{3}(\mathrm{THF})_{4}\right]$ under anhydrous conditions but the related benzimidazole tripodes $\mathbf{5 7}$ and $\mathbf{5 8}$ formed 1:2 complexes with U(III). ${ }^{53}$ Solution NMR studies showed a greater stability of the 1:2 complexes of U(III) and La(III) with these ligands than with tris[(2pyridyl)methyl]amine 51, due to the presence of $\pi-\pi$ stacking in the benzimidazole complexes. However, successive formation of 1:1 and 1:2 complexes of tris[(2-pyridyl)methyl]amine $\mathbf{5 1}$ with the lanthanides was observed on addition of $\mathbf{5 1}$ to $\mathrm{Ln}(\mathrm{OTf})_{3}$ and $\left[\mathrm{LnI}_{3}(\mathrm{THF})_{4}\right]$ under rigorously anhydrous conditions, and the structures of the 1:2 complexes have been determined. ${ }^{54}$

Analysis of lanthanide-induced proton NMR shifts show that tris[(2-pyridyl)methyl]amine $\mathbf{5 1}$ and its triamide derivative $\mathbf{5 3}$ have very similar formation constants, although the thermodynamic driving force for complex formation differs in each case. Whereas complexation of tris[(2-pyridyl)methyl]amine $\mathbf{5 1}$ is largely enthalpy-driven, complexation with $\mathbf{5 3}$ is completely driven by entropy. ${ }^{55}$ The additional ligating sites present in $\mathbf{5 3}$ displace more water molecules from the hydrated lanthanide ion during complex formation than 51. X-ray absorption spectroscopy (EXAFS) on An(III) and Ln(III) complexes of tris[(2-pyrazinyl)methyl]amine $\mathbf{5 2}$ showed no obvious structural differences between the two sets of complexes, ${ }^{56}$ although relatively short U(III)-N bond distances were observed, suggesting a higher degree of covalent character.

The tetrapodal, hexadentate ligand $N, N, N^{\prime}, N^{\prime}-$ tetrakis[(2-pyridyl)methyl]-ethylenediamine (TPEN) 59 showed more promising results. In the absence of a synergist, solutions of $\mathbf{5 9}$ in nitrobenzene selectively extracted $\mathrm{Am}(\mathrm{III})$ over $\mathrm{Eu}(\mathrm{III})$ from $\mathrm{NH}_{4} \mathrm{NO}_{3}$ solutions $(\mathrm{pH}=4)$ as their 1:1 complexes with high efficiency and selectivity $\left(D_{\mathrm{Am}} \sim 100, \mathrm{SF}_{\mathrm{Am} / \mathrm{Eu}} \sim 100\right.$ for $10 \mathrm{mM}$ solutions of 59). The results were broadly similar in the preferred diluent 1-octanol in the presence of decanoic acid as synergist. although the system did not extract from more acidic $(\mathrm{pH}<4)$ aqueous solutions. ${ }^{57}$ The related TPEN isomers 60 and 61 showed no significant extraction of either Am(III) or $\mathrm{Eu}(\mathrm{III})$, indicating the importance of the position of the N-donor atoms in the pyridine rings. ${ }^{58}$

Pyrazine containing analogues of TPEN 59 with different diamino spacers were then investigated. Excellent results were obtained in the extraction of $\mathrm{Am}(\mathrm{III})$ and $\mathrm{Eu}(\mathrm{III})$ into TPH solution by $N, N, N^{\prime}, N^{\prime}-$ tetrakis[(2-pyrazinyl)methyl]-ethylenediamine $\mathbf{6 2}$ in the presence of 2-bromodecanoic acid $\left(D_{\mathrm{Am}}=45\right.$, $\mathrm{SF}_{\mathrm{Am} / \mathrm{Eu}}=70$ for $0.1 \mathrm{M} 62$ from $0.03 \mathrm{M} \mathrm{HNO}_{3}$ ). Interestingly, $N, N, N$ ', $N$ '-tetrakis[(2-pyrazinyl)methyl]propanediamine 63 , which has a longer spacer and is thus more flexible, shows good extraction ability but no selectivity $\left(\mathrm{SF}_{\mathrm{Am} / \mathrm{Eu}}=1.5-2.3\right)$ under similar conditions. ${ }^{59}$ The more rigid ligand 64 bearing a trans1,2-diaminocyclohexane spacer showed no significant extraction of either metal ion. The drastic difference in selectivity between 62 and 63 or 64 was explained by the different preferred conformations of the ligands which was reflected in the X-ray structures of their 1:1 complexes with La(III).

More recently, tris(2-pyridyl)methanol $\mathbf{6 5}$ and analogues have been studied as potential An(III)selective extractants. These ligands are synthesized as shown in Scheme 5 by addition of lithiated 2bromopyridines to triphosgene, carbonyldiimidazole or bis(2-pyridyl)ketones. ${ }^{60}$ At $\mathrm{pH}>4.7$, tris(2pyridyl)methanol 65 selectively extracted Am(III) in synergistic combination with picric acid into nitrobenzene, 1,2-dichloroethane or chloroform with $\mathrm{SF}_{\mathrm{Am} / \mathrm{Eu}}$ of 6.7-9.6. The corresponding methyl ether $\mathbf{6 6}$ showed similar selectivity but the $D$ values were about three orders of magnitude lower. ${ }^{61}$ The ligands extracted Am(III) as 1:3 complexes. Unusual homodinuclear 2:2 lanthanide complexes were obtained on treatment of tris(2-pyridyl)methanol $\mathbf{6 5}$ 
with $\mathrm{La}(\mathrm{OTf})_{3} \cdot 3 \mathrm{H}_{2} \mathrm{O}$. Each ligand coordinated in a tetradentate bridging mode with $\mu$-oxo bridges formed by the hydroxyl groups of $\mathbf{6 5} .^{62}$

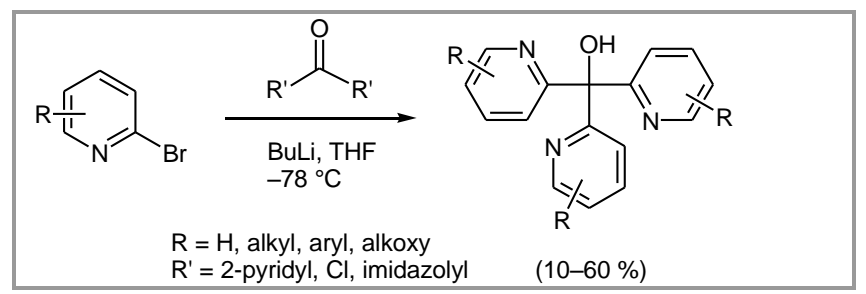

Scheme 5 Synthesis of tris(2-pyridyl)methanol ligands

\section{BTP and Related Ligands}

Terdentate ligands based on 2,6-bis(1,2,4-triazin-3yl)pyridine (BTP) were first synthesized by Case in 1971. ${ }^{63}$ BTPs are typically synthesized by the condensation reaction of pyridine-2,6dicarbohydrazonamide with a 1,2-diketone (Scheme 6). Related 1,2,4-triazine-substituted pyridines have found use as synthetic precursors to functionalized oligopyridines. $^{64}$ In 1999, Kolarik reported that alkylsubstituted BTPs and related 2,6-bis(1,2,4triazolyl)pyridines separated $\mathrm{Am}(\mathrm{III})$ from $\mathrm{Eu}(\mathrm{III})$ with very high selectivity $\left(\mathrm{SF}_{\mathrm{Am} / \mathrm{Eu}} \leq 150\right){ }^{65}$ The BTP and related ligands that were screened for their ability to selectively extract $\mathrm{Am}(\mathrm{III})$ from $\mathrm{Eu}(\mathrm{III})$ are summarized in Table 6.

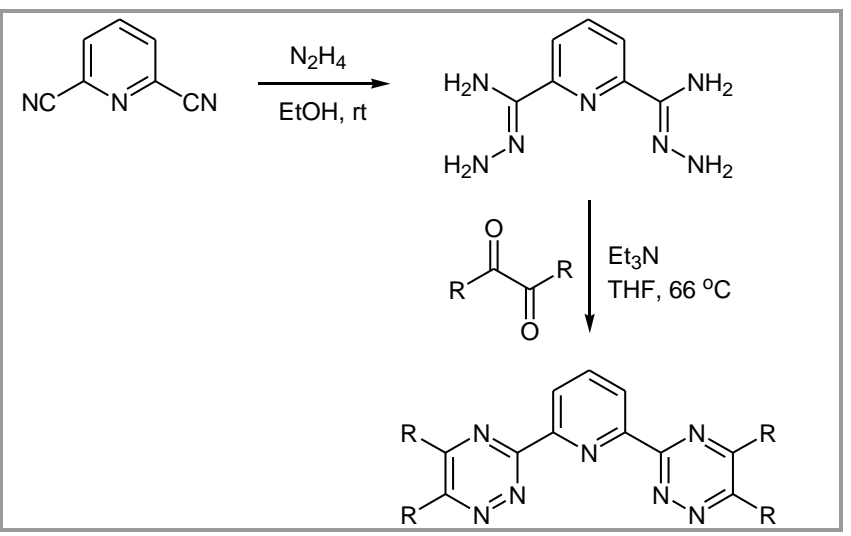

Scheme 6 Synthesis of 2,6-bis(1,2,4-triazin-3-yl)pyridine ligands

The extraction by the triazolyl-based ligands depended strongly on the diluent composition used and a synergist (2-bromohexanoic acid) was required for efficient extractions. The related oxadiazolyl-based ligands performed similarly, but with lower extraction selectivity $\left(\mathrm{SF}_{\mathrm{Am} / \mathrm{Eu}} \leq 23.3\right) .{ }^{66}$ In contrast, not only were the BTP ligands able to selectively extract Am(III) with very high efficiency $\left(1 \leq D_{\mathrm{Am}} \leq 61\right)$ in the absence of a lipophilic anion source (ie: $\mathrm{Am}\left(\mathrm{NO}_{3}\right)_{3}$ was extracted), but they could also extract efficiently from solutions of high acidity $\left(\left[\mathrm{HNO}_{3}\right] \geq 1 \mathrm{M}\right)$. This was a key breakthrough because up to this point, other heterocyclic $N$-donor ligands required synergists such as 2-bromodecanoic acid for efficient extractions, and were unable to extract from highly acidic solutions that would be present in an industrial SANEX process.

Further solvent extraction studies were carried out on the most promising BTPs; the dipropyl- and diisopropyl-substituted BTPs $\mathbf{7 0}$ and 71 (Table 6). The dependence of $D_{\mathrm{Am}}$ and $D_{\mathrm{Eu}}$ on the ligand concentrations showed that the metals were extracted as trisolvates of stoichiometry $\left[\mathrm{ML}_{3}\right]\left(\mathrm{NO}_{3}\right)_{3}{ }^{67}$ The rate of $\mathrm{Am}(\mathrm{III})$ extraction was determined by the rate of complexation of the metal, and increased linearly with [BTP] but decreased as $\left[\mathrm{HNO}_{3}\right]$ increased, due to competing protonation of the BTP. ${ }^{68}$ Initial attempts to isolate and structurally characterize the 1:3 complexes of BTP ligands with the lanthanide nitrates were unsuccessful. Only complexes in which the cation contained one or two BTP ligands were obtained, ${ }^{69}$ including an unusual 12-coordinate complex with $\mathrm{Nd}$ and $\operatorname{Pr}^{70}$ Structural and theoretical studies with the related bistriazolylpyridine ligands $\mathbf{7 9}$ and $\mathbf{8 0}$ showed that only complexes containing one ligand and one or more nitrates in the metals inner coordination sphere were formed. ${ }^{71}$

Eventually, the X-ray crystal structures of the 1:3 complexes of dipropyl-BTP 70 with Sm(III), Tm(III) and $\mathrm{Yb}(\mathrm{III})$ nitrates were obtained and showed that the metal ions were completely enclosed by three ligands while the nitrates were displaced to the outer coordination sphere of the metal. ${ }^{72}$ This provided the first structural evidence for the type of complexes that were involved in the extraction processes. Similarly, BTP complexes of 1:3 stoichiometry were also observed with $\mathrm{La}(\mathrm{III}), \mathrm{Ce}(\mathrm{III})$ and U(III) iodides and triflates. $^{73}$ The formation of highly lipophilic $1: 3$ complexes with the BTPs in the presence of nitrate ions, rather than the $1: 1$ or $1: 2$ complexes observed with related terdentate $\mathrm{N}$-donor ligands, is likely to be responsible for the greatly improved extraction by this remarkable class of ligands. Quantum mechanics calculations suggest that it will be possible to tune the affinity (and basicity) of the BTP ligands through substituent effects, ${ }^{74}$ although this remains to be studied by solvent extraction.

Numerous studies also point to the formation of $1: 3$ complexes by the BTPs in solution. Electrospray ionization mass spectrometry and time-resolved laserinduced luminescence studies of the complexation of BTPs with $\mathrm{Ln}(\mathrm{III})$ in acidic $\mathrm{H}_{2} \mathrm{O} / \mathrm{MeOH}$ solutions show the presence of stable $\operatorname{Ln}(\mathrm{BTP})_{3}{ }^{3+}$ complexes. In the more relevant diluent 1-octanol, complexes of 1:1, $1: 2$ and 1:3 stoichiometry are observed in different relative abundances depending on the lanthanide and the ligand:metal ratio used. ${ }^{75}$ In comparison, Am(III), $\mathrm{Cm}(\mathrm{III})$ and $\mathrm{Pu}(\mathrm{III})$ exclusively form 1:3 complexes with the BTPs which are thermodynamically more stable than the 1:3 complexes formed with 
Table 6 BTP and related ligands studied for their ability to extract and separate An(III) from Ln(III)

Ligand Structure
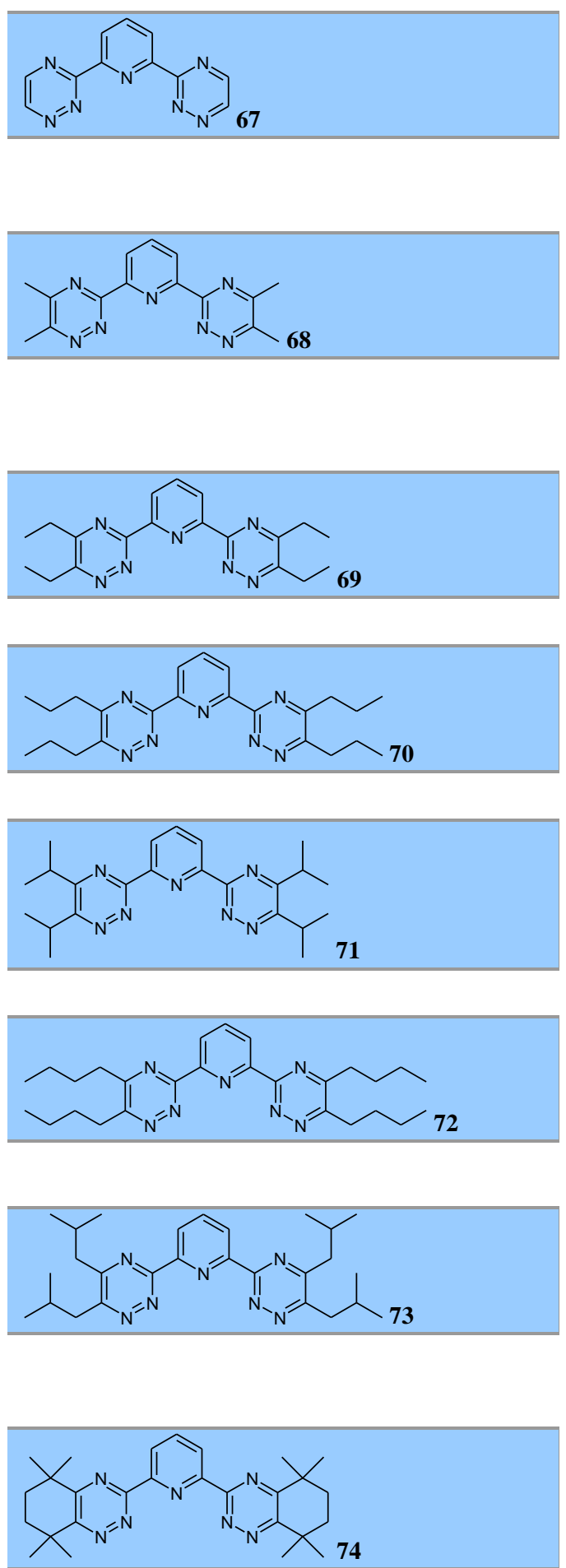

74

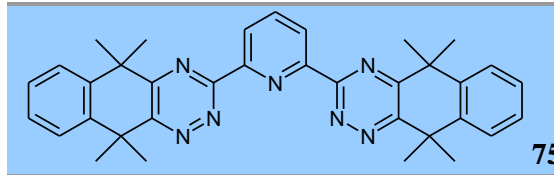

References

70,78

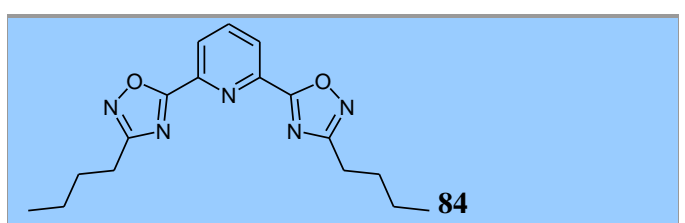

$65,69,73$, $74,75 \mathrm{a}, 75 \mathrm{~b}$
$75 \mathrm{c}, 76 \mathrm{~b}, 77$

$78,85,91$

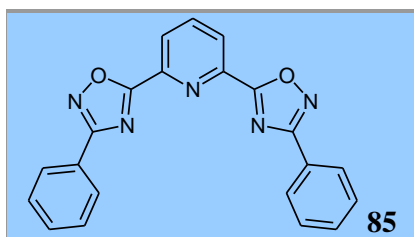

$65,69,82 \mathrm{~b}$,

$84,85,91$

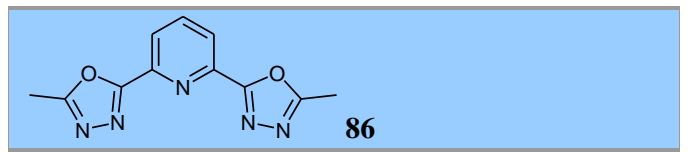

$56,65,67$,

$68,72,73$,

$75,76 \mathrm{a}, 76 \mathrm{c}$

76d, 77, 98

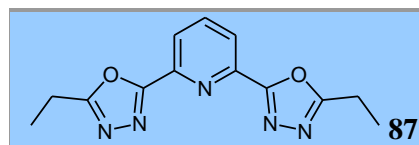

$67,75 a, 75 b$

$65,82 \mathrm{a}$

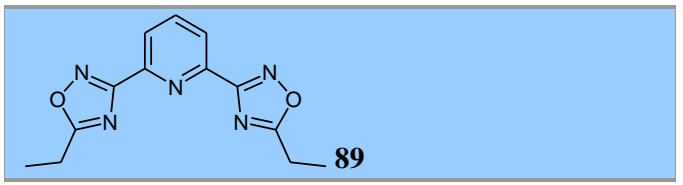

65,69

$74,79,117$

References

66

66

66

66

66

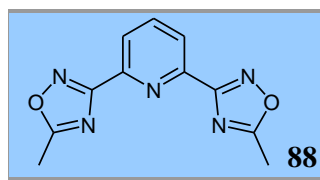

66

66

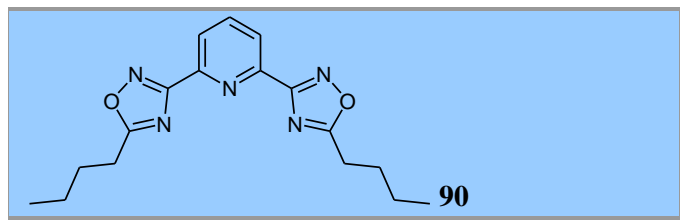

66

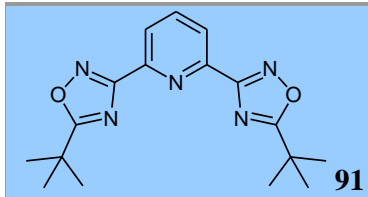

117

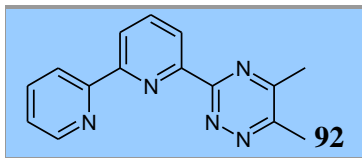


65,85

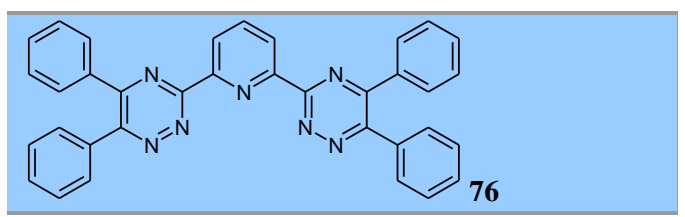

65

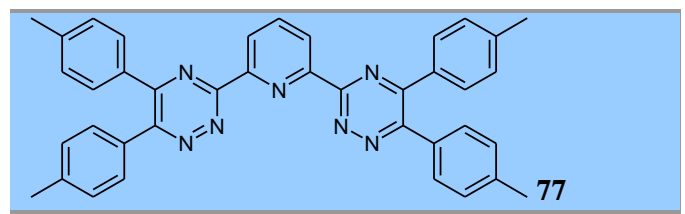

65

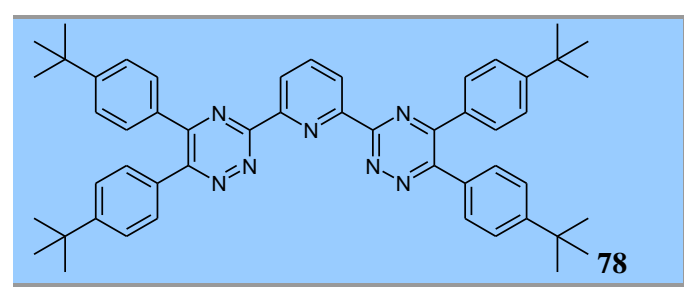

65,71

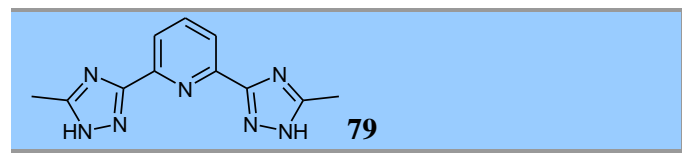

65,71

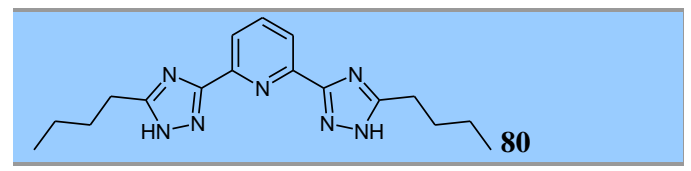

65

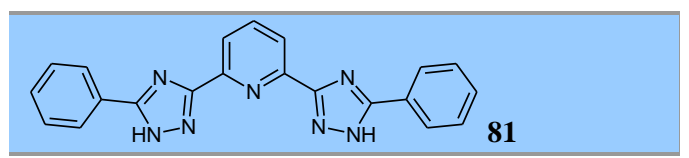

66

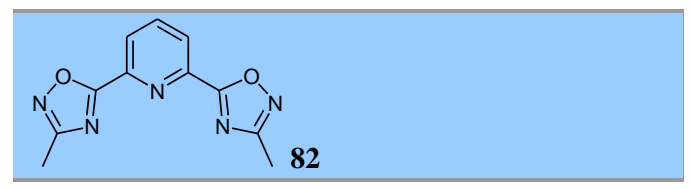

66

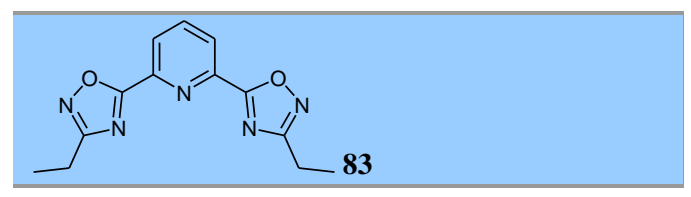

Eu(III). ${ }^{76,56}$ The difference in stability is mainly enthalpic, pointing to a stronger bonding interaction of the BTPs with An(III) than with Ln(III).

Unusual X-ray crystallographic structures of both 1:1

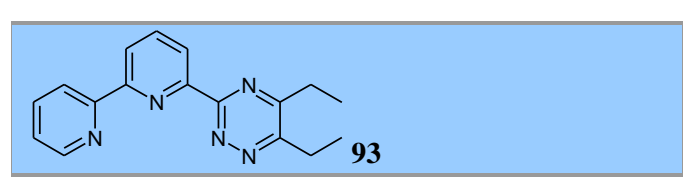

$85,88,89$,

91

91,98

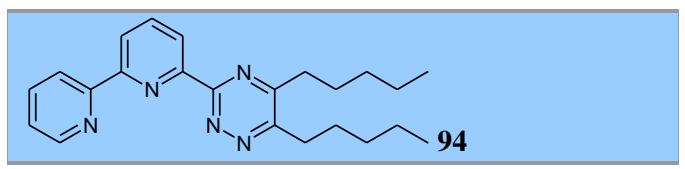

89

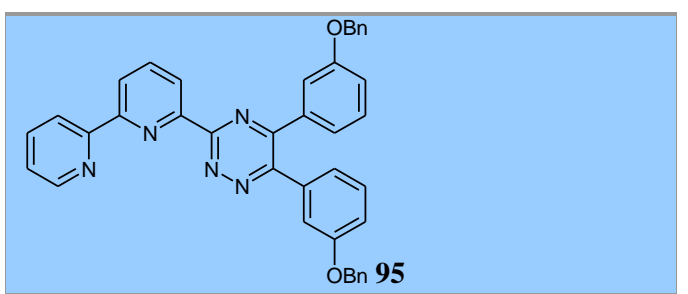

91

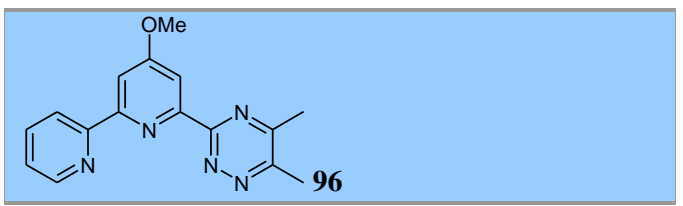

91

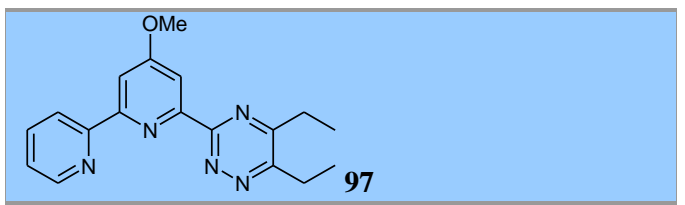

92

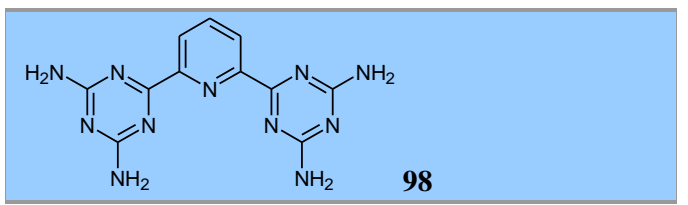

92

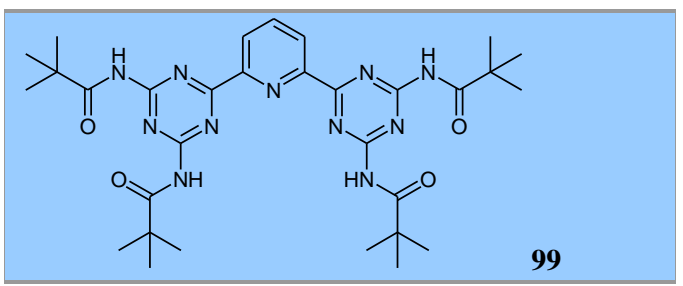

90

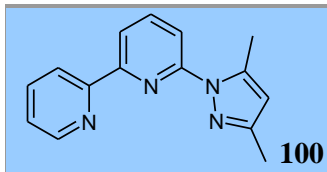

and 1:2 BTP complexes with the linear uranyl $\left(\mathrm{UO}_{2}{ }^{2+}\right)$ cation have been reported. ${ }^{77}$ DFT calculations for the 1:1 complexes showed that the bonding energy in the corresponding TERPY complex was more negative than the BTP complex, and TERPY made a greater orbital contribution to the bonding than BTP. 
However, the nature of the orbitals involved differed between the two complexes. In the TERPY complex, the bonding was essentially between the $\mathrm{UO}_{2}{ }^{2+}$ ion and the $\mathrm{NO}_{3}{ }^{-}$ion, or between the $\mathrm{UO}_{2}{ }^{2+}$ ion and TERPY, whereas in the BTP complex a molecular orbital interaction involving the $\mathrm{UO}_{2}{ }^{2+}$ ion, $\mathrm{NO}_{3}{ }^{-}$ions and the triazine rings is found. In this orbital, the lone pair of the nitrogen adjacent to the ligating nitrogen of the triazine ring contributes to the bonding, suggesting that this nitrogen plays an important role in the high selectivity of the BTPs towards An(III). For a series of terdentate nitrogen heterocyclic ligands, $a b$ initio calculations of trivalent lanthanide complexes show that complex stability increases as the electron donor ability of the central nitrogen increases and as the electron acceptor ability of the lateral nitrogens increases. $^{78} \mathrm{~A}$ thermodynamic model has been developed which suggests that, for 4-amino-bis(2,6(2-pyridyl))-1,3,5-triazine (ADPTZ) 35, the complexation with $\operatorname{Ln}(\mathrm{III})$ is enthalpy driven whereas for BTPs, the complexation is entropy driven.

The behavior of BTPs in their neutral, protonated and complexed forms at oil/water interfaces were investigated using molecular dynamics simulations. It was found that the neutral ligands were weakly surface active, whereas the protonated ligands strongly adsorbed at the interfaces with neutral or acidic water. ${ }^{79}$ Interestingly, the $\mathrm{NH}^{+}$group of the protonated ligands point towards the oil phase, rather than the aqueous phase. It appears that complexation occurs right at the interface via the protonated ligand, explaining why the extraction of Am(III) and $\mathrm{Eu}(\mathrm{III})$ increases as $\left[\mathrm{HNO}_{3}\right]$ increases. The 1:3 complexes $\mathrm{Eu}(\mathrm{BTP})_{3}{ }^{3+}$ were also highly surface active, and attracted by water at the interface. The role of synergists such as long chain carboxylic acids and dicarbollide anions appears to be to promote the formation and extraction of the 1:3 complexes adsorbed at the interface by attracting the $\mathrm{Eu}^{3+}$ and $\mathrm{BTPH}^{+}$cations which would otherwise repel each other. $^{80}$

Laboratory scale SANEX processes were designed and sucessfully implemented using the dipropyl- and diisopropyl-substituted BTPs $\mathbf{7 0}$ and $\mathbf{7 1}$ (Table 6). ${ }^{81}$ Promising results have also been obtained in the separation of Am(III) from $\mathrm{Ln}(\mathrm{III})$ by BTPs immobilized on silica-based resins and supported liquid membranes. ${ }^{82}$ However, in further process development studies it was found that the dialkylsubstituted BTPs were susceptible to acid-catalyzed hydrolysis and radiolytic degradation leading to a decrease in the extraction performance of the diluent. $^{83}$ This ultimately renders these ligands unsuitable for industrial use, although it has been shown that the addition of nitrobenzene to the organic phase appears to increase the radiolytic stability of the BTPs by acting as a radical scavenger. ${ }^{84}$

At this point, multiple parallel synthesis of a library of 1,2,4-triazine-containing $N$-heterocycles was carried out in order to identify potentially new ligands for the partitioning of $\mathrm{An}(\mathrm{III})$ from $\mathrm{Ln}(\mathrm{III}) .{ }^{85}$ The ligands were synthesized by condensing amide hydrazides with 1,2-diketones. The amide hydrazides were prepared by the reaction of hydrazine with either a 2cyanopyridine or dithiooxamide. ${ }^{86}$ The 2cyanopyridines were synthesized by oxidation of the parent pyridines using hydrogen peroxide in acetic acid, followed by a modified Reissert-Henze reaction of the resulting pyridine $\mathrm{N}$-oxides. ${ }^{87}$ The best results were observed for the tridentate BTPs and the 6(1,2,4-triazin-3-yl)-2,2'-bipyridines (hemi-BTPs), in which one of the triazine rings of the BTP has been replaced by a pyridine ring (Scheme 7). None of the bidentate ligands showed any useful extraction properties or $\mathrm{Am} / \mathrm{Eu}$ selectivity. The hemi-BTP ligands were subsequently chosen for further study.

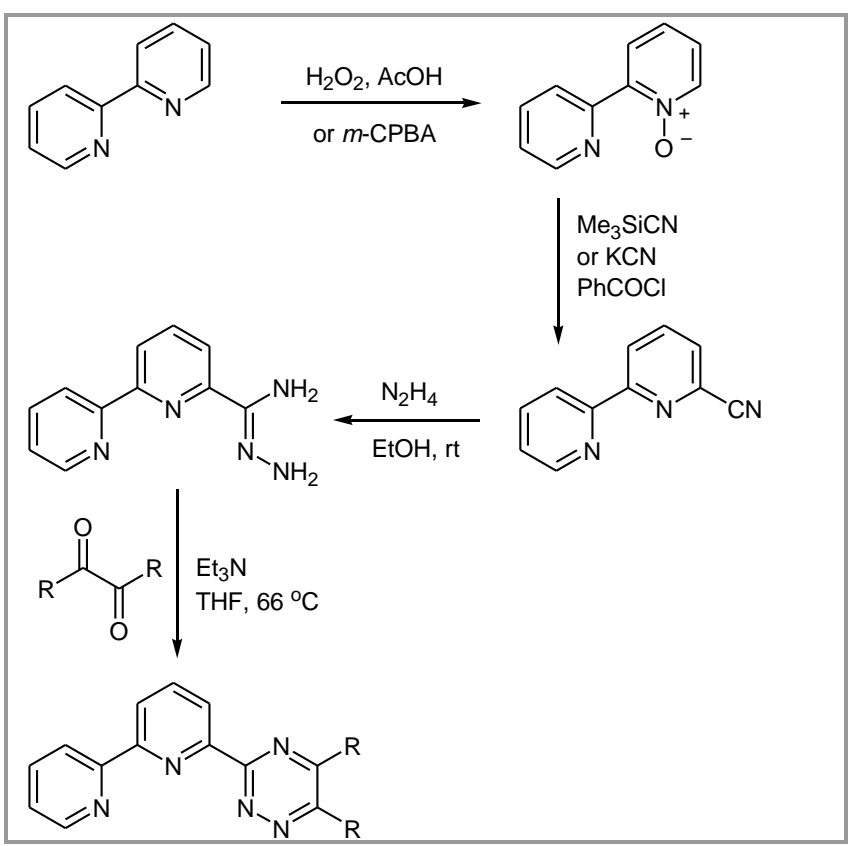

Scheme 7 Synthesis of 6-(1,2,4-triazin-3-yl)-2,2'-bipyridine ligands

It was found that the hemi-BTPs have properties intermediate between those of the 2,2':6',2',terpyridines and the BTPs and resemble more closely the $2,2^{\prime}: 6$ ',2"'terpyridine ligands. ${ }^{88}$ Although useful selectivities were observed $\left(\mathrm{SF}_{\mathrm{Am} / \mathrm{Eu}} \leq 30\right)$, diethyl hemi-BTP 93 (Table 6) could only extract from nitric acid solutions of low acidity $\left(\left[\mathrm{HNO}_{3}\right] \leq 0.1 \mathrm{M}\right)$ and in the presence of the synergist 2-bromodecanoic acid. Similarly, di(benzyloxyphenyl) hemi-BTP 95 selectively extracted Am(III) only from weakly acidic aqueous solutions into octanol or nitrobenzene in synergistic combination with chlorinated cobalt dicarbollide (COSAN) which acts as a hydrophobic anion source. ${ }^{89}$ The formation of both $1: 1$ and $1: 2$ complexes of the hemi-BTPs with lanthanide(III) nitrates was observed by ${ }^{1} \mathrm{H}$ NMR titrations and X-ray crystallography but, unlike the BTPs, there was no evidence for the formation of the more hydrophobic 
1:3 complexes. In addition, the ligands were susceptible to decomposition via hydrolysis of the triazine ring in a mixture of nitrous acid and nitric acid. ${ }^{88}$ Replacing the 1,2,4-triazine ring of the hemiBTPs with a pyrazol-1-yl ring does not improve the extraction properties, and the resulting ligand $\mathbf{1 0 0}$ only extracts $\mathrm{Am}(\mathrm{III})$ and $\mathrm{Eu}(\mathrm{III})$ from weakly acidic solutions with modest $\left(\mathrm{SF}_{\mathrm{Am} / \mathrm{Eu}} \leq 8\right)$ selectivity. ${ }^{90}$

The extraction of various transition metals such as $\mathrm{Mn}(\mathrm{II}), \mathrm{Ni}(\mathrm{II}), \mathrm{Sr}$ (II), $\mathrm{Zr}$ (IV), $\mathrm{Ru}(\mathrm{II}), \mathrm{Cd}(\mathrm{II}), \mathrm{Pb}(\mathrm{II})$ and $\mathrm{Ba}$ (II) by the BTP and the hemi-BTP ligands was investigated since many of these elements are present in the raffinate produced by the PUREX process. For BTP 69 and hemi-BTP 94, many of these metals were extracted into the organic phase with $D$ values in some cases higher than that observed for Am(III). ${ }^{91}$ This is significant since these metals in high enough concentrations could disrupt an Am(III) extraction process by sequestering the extractant. A number of homoleptic octahedral complexes of the hemi-BTPs with $\mathrm{Mn}(\mathrm{II}), \mathrm{Fe}(\mathrm{II}), \mathrm{Co}(\mathrm{II})$ and $\mathrm{Zn}(\mathrm{II})$ were also characterized by X-ray crystallography.

Terdentate ligands posessing two outer 1,3,5-triazine rings were then studied to determine if the presence of two adjacent nitrogen atoms in the 1,2,4-triazine rings of the BTPs was responsible for the superior properties of the BTP ligands. The 2,6-bis(1,3,5triazin-2-yl)pyridines 98 and 99 were synthesized by the reaction of pyridine-2,6-dicarbonitrile and dicyandiamide, followed by acylation of the aminogroups with pivaloyl chloride (in the case of 99). In solvent extraction experiments, the performance of $\mathbf{9 8}$ and 99 was considerably worse than the BTPs under similar conditions either in the presence or absence of a synergist. ${ }^{92}$ Very low distribution ratios and only moderate separation factors $\left(\mathrm{SF}_{\mathrm{Am} / \mathrm{Eu}} \leq 6\right)$ were observed. This study suggested that the unique properties of the BTPs are indeed related to the presence of two adjacent nitrogen atoms in the triazine rings.

\section{BTBP and Related Ligands}

The susceptibility of the BTP ligands to hydrolysis and radiolysis prompted us to investigate analogous quadridentate ligands. Process development studies on the BTPs also revealed that the back-extraction (stripping) of $\mathrm{An}$ (III) from a loaded organic phase could not be accomplished. This was probably due to the ability of three BTP ligands to enclose completely the inner coordination sphere of the metal. On the other hand, a quadridentate bis-triazine ligand would be expected to have a weaker ligand field and perhaps form less stable 1:1 and/or 1:2 complexes which would leave sufficient room for water, nitrate or stripping agents to coordinate to the metal and displace the ligands. The 6,6'-bis(1,2,4-triazin-3-yl)2,2'-bipyridine (BTBP) ligands were subsequently investigated.
The BTBP ligands are typically synthesized as shown in Scheme 8. Oxidation of 2,2'-bipyridine with hydrogen peroxide in acetic acid ${ }^{93}$ and Reissert-Henze reaction of the resulting bis- $N$-oxide affords the dinitrile. ${ }^{94}$ The addition of hydrazine to the dinitrile generates the diamide dihydrazide ${ }^{64}$ which is condensed with a 1,2-diketone to form the BTBP. BTBPs have previously been employed as synthetic precursors to substituted quaterpyridine ligands. ${ }^{64}$ The BTBP and related ligands that were synthesized and tested for their ability to selectively extract Am(III) from $\mathrm{Eu}(\mathrm{III})$ are shown in Table 7.

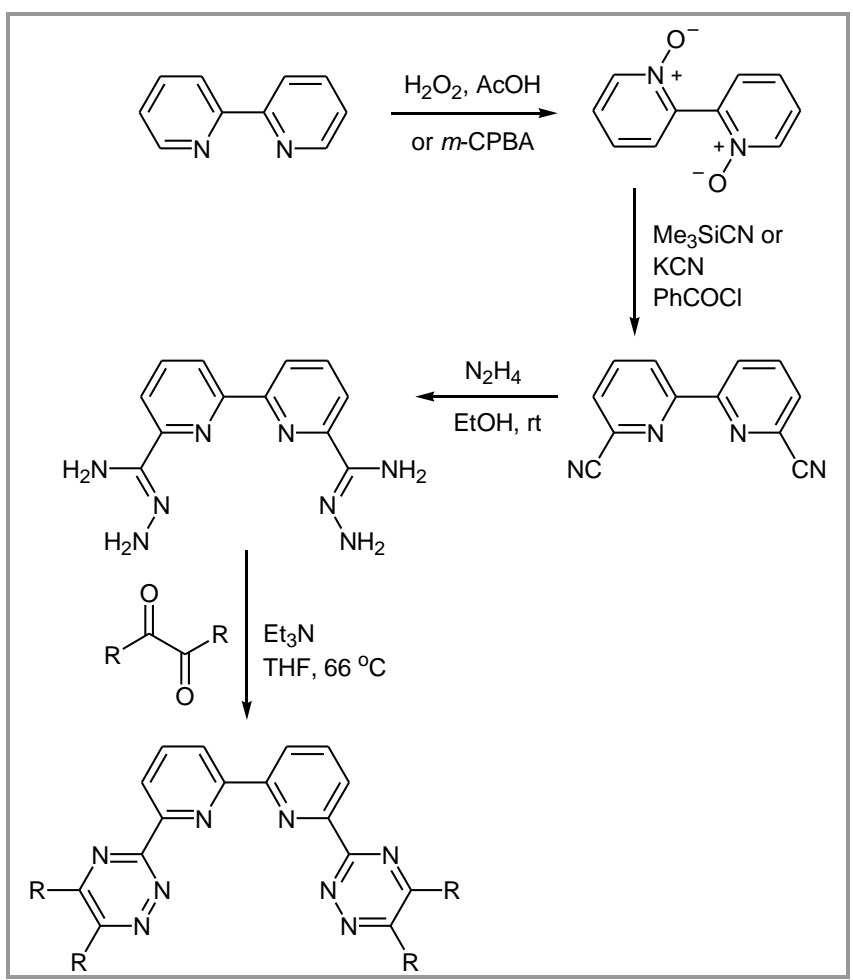

Scheme 8 Synthesis of 6,6'-bis(1,2,4-triazin-3-yl)-2,2'-bipyridine ligands

Initial studies with diethyl-BTBP $\mathbf{1 0 2}$ showed promising results. Both high affinity for $\mathrm{Am}(\mathrm{III})\left(D_{\mathrm{Am}}\right.$ $=650 \pm 33$ ) and high selectivity for Am(III) over $\mathrm{Eu}$ (III) $\left(\mathrm{SF}_{\mathrm{Am} / \mathrm{Eu}}=160 \pm 16\right)$ were observed in the extraction of the metals from $1 \mathrm{M} \mathrm{HNO}_{3}$ by a $0.068 \mathrm{M}$ solution of $\mathbf{1 0 2}$ in 1,1,2,2-tetrachloroethane. ${ }^{95}$ The somewhat slow kinetics of extraction could be accelerated using phase-transfer reagents. ${ }^{96}$ Lanthanide nitrate complexes of formula $\left[\mathrm{LaL}\left(\mathrm{NO}_{3}\right)_{3}\right]$ were synthesized and characterized by X-ray crystallography. The structures showed the lanthanides were coordinated to one planar tetradentate BTBP ligand and three bidentate nitrate ions in a 10-coordinate environment of $\mathrm{C}_{2}$ symmetry. ${ }^{97}$ No solid state evidence was observed for the formation of 1:2 complexes but NMR titrations with $\mathrm{La}\left(\mathrm{NO}_{3}\right)_{3}$ and $\mathrm{Y}\left(\mathrm{NO}_{3}\right)_{3}$ showed the presence of 
Table 7 BTBP and related ligands studied for their ability to extract and separate An(III) from Ln(III)

Ligand Structure

References
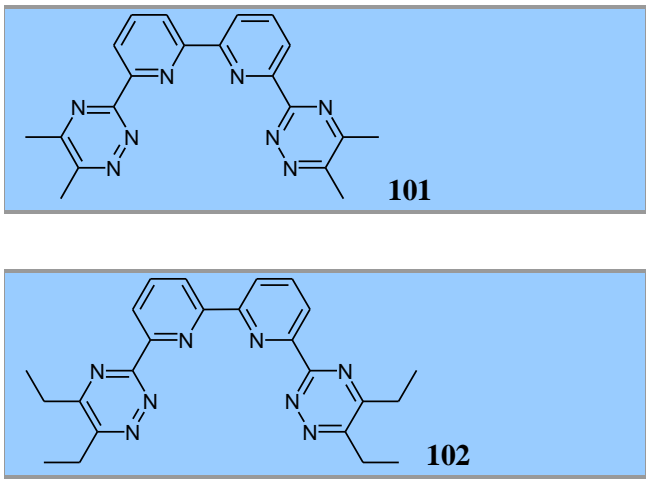

$95,96,97$,

102, 103,

111,118

110,111 ,

118

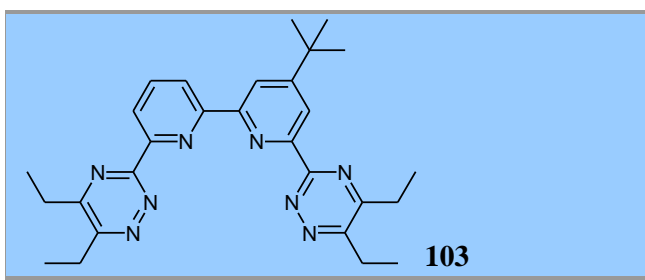

97, 102
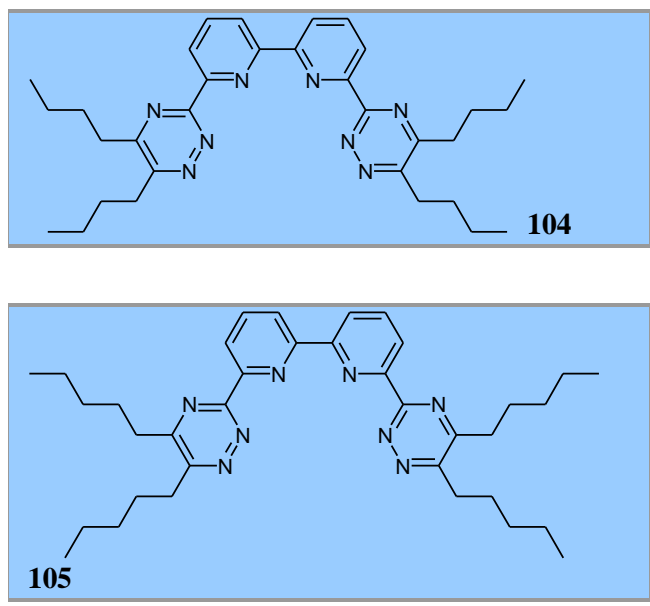

97, 98, 99,

100, 101,

102,103 ,

107, 116,

118, 119

97,102
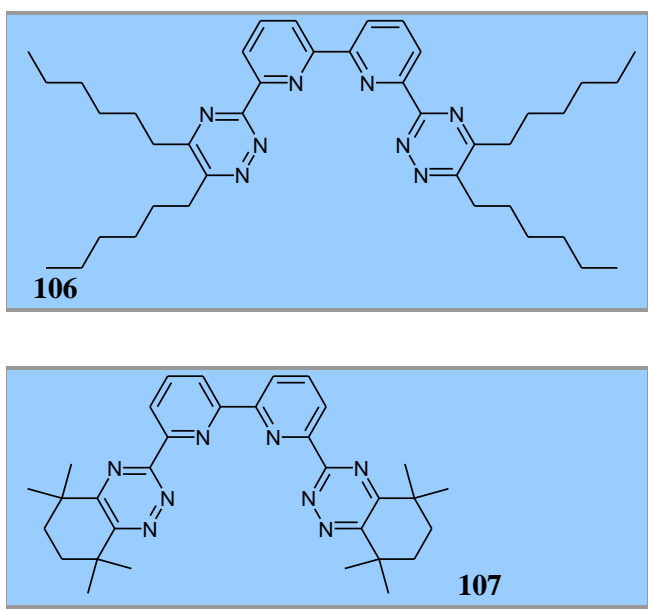

77, 97, 98,

99, 102,

104, 105,

106, 107,

108, 109,

111,118 ,

119, 121

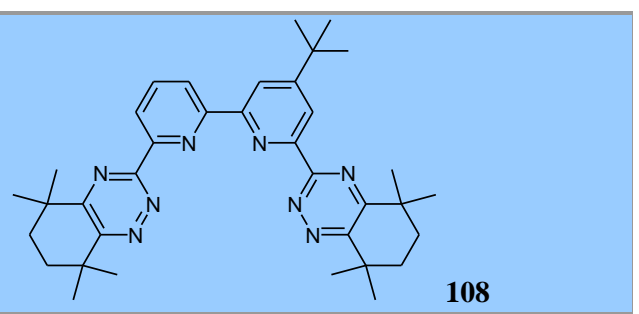

111,118

120

112

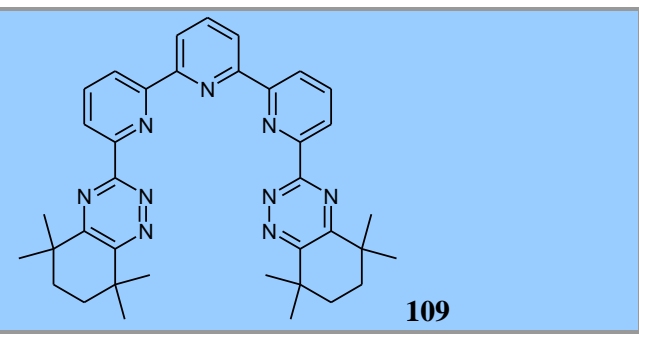

both 1:1 and 1:2 complexes in solution. Further evidence for the formation of complexes of these stoichiometries was obtained from spectrophotometric titrations of dipentyl-BTBP $\mathbf{1 0 5}$ and $\mathrm{CyMe}_{4}$-BTBP 107 with $\mathrm{La}(\mathrm{III})$, Eu(III) and $\mathrm{Yb}(\mathrm{III})$ in methanol. ${ }^{98}$ However, only the 1:2 complexes of $\mathrm{CyMe}_{4}$-BTBP 107 and dipentyl-BTBP 105 with Am(III) in various diluents were observed by electrospray ionization mass spectrometry. ${ }^{99}$

Further detailed solvent extraction studies were carried out on more lipophilic BTBPs bearing longer alkyl side chains. Dipentyl-BTBP $\mathbf{1 0 5}$ showed variable distribution ratios but high separation factors in the extraction of $\mathrm{Am}$ (III) and Eu(III) into a range of organic diluents which suggested that back extraction of the metals would be possible through careful choice of diluent and by adjusting the acidity of the aqueous phase. $^{100}$ The most suitable diluent was cyclohexanone and rapid extraction kinetics were observed in this diluent (equilibrium was reached within 5 minutes). ${ }^{101}$ Another feature of the BTBPs is that, like the BTPs, the extraction of both Am(III) and $\mathrm{Eu}(\mathrm{III})$ increases as $\left[\mathrm{HNO}_{3}\right]$ increases.

The thermodynamics of the extraction showed that Am(III) had a more negative Gibbs free energy of extraction than $\mathrm{Eu}(\mathrm{III})$. Back extraction of $\mathrm{Am}$ (III) using glycolic acid and recycling of the organic phase were successfully demonstrated showing that, unlike the BTP ligands, a continuous extraction process was feasible. However, $\mathbf{1 0 5}$ was sensitive to radiolysis and $D_{\text {Am }}$ decreased by ca. $80 \%$ on exposure of the diluent to ca. $17 \mathrm{kGy}$ of gamma radiation. ${ }^{100}$

The extraction of Am(III), Th(IV), Np(V) and U(VI) by a range of BTBP ligands has been investigated to determine the effect of the oxidation state of the actinide ions on their extraction. ${ }^{102}$ It was found that the extraction increased in the order $\mathrm{Am}(\mathrm{III})<\mathrm{Th}$ (IV) $<\mathrm{Np}(\mathrm{V})<\mathrm{U}(\mathrm{VI})$ at low BTBP concentrations but increased in the order $\mathrm{Th}(\mathrm{IV})<\mathrm{U}(\mathrm{VI})<\mathrm{Np}(\mathrm{V})<$ 
Am(III) at high BTBP concentrations. This study suggests that the trivalent and pentavalent actinides can be separated from the tetravalent and hexavalent actinides using the BTBPs. In addition, the BTBPs also extracted several D-block metals to a significant extent, in common with the terdentate BTP and hemiBTP ligands. ${ }^{100,103}$

The most promising of the BTBP ligands is $\mathrm{CyMe}_{4}{ }^{-}$ BTBP 107, which is designed to be more resistant to radiolysis (this will be discussed in detail later). This ligand is the most studied of the BTBP ligands, and its solvent extraction chemistry has been studied in detail. ${ }^{104}$ High selectivities were observed for Am(III) and $\mathrm{Cm}$ (III) over the entire lanthanide series including yttrium. When dissolved in 1-octanol $(0.02 \mathrm{M})$, the ligand gave $D_{\mathrm{Am}}=$ ca. 4.5 and $\mathrm{SF}_{\mathrm{Am} / \mathrm{Eu}}=$ ca. 140 in the extraction of $\mathrm{Am}(\mathrm{III})$ and $\mathrm{Eu}(\mathrm{III})$ from $0.5 \mathrm{M} \mathrm{HNO}_{3}$, and equilibrium was reached within 60 minutes. The slow kinetics of extraction was considerably improved by the addition of DMDOHEMA 4 (Figure 1) to the organic phase, and equilibrium was reached after only 5 minutes. The dependence of $D_{\mathrm{Am}}$ on [CyMe 4 -BTBP] showed the metals were extracted as 1:2 complexes. The ligand showed excellent hydrolytic stability on long term (2 months) exposure to $1 \mathrm{M} \mathrm{HNO}_{3}$ with no

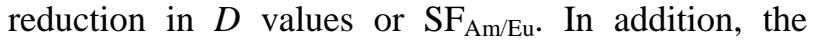
selective back-extraction of the lanthanides (scrubbing), followed by the actinides (stripping) was accomplished using aqueous solutions of $0.5 \mathrm{M} \mathrm{HNO}_{3}$ and $0.5 \mathrm{M}$ glycolic acid at $\mathrm{pH} 4$, respectively.

After some optimization of the conditions, ${ }^{105}$ a laboratory scale SANEX process was successfully demonstrated on a genuine spent fuel solution using $\mathrm{CyMe}_{4}$-BTBP 107 and DMDOHEMA 4 dissolved in 1-octanol. ${ }^{106}$ The counter current extraction process was carried out in centrifugal contactors and comprised 16 stages $(9$ stages for extraction, 3 stages for lanthanide back-extraction and 4 stages for actinide back-extraction). More than $99.9 \%$ of the $\mathrm{Am}$ (III) and $\mathrm{Cm}$ (III) were recovered from the $2 \mathrm{M}$ $\mathrm{HNO}_{3}$ feed solution and more than $99.9 \%$ of the lanthanides were directed to the raffinate.

$\mathrm{CyMe}_{4}$-BTBP 107 has also been investigated as a potential ligand for a GANEX (Group ActiNide EXtraction) separation process. In this process, it is planned to selectively extract the actinides directly from the PUREX raffinate, removing the need for a preceeding DIAMEX process. Under these conditions, the actinides will need to be extracted in different oxidation states and the metal loading of the aqueous phase will be far higher than in a SANEX process. Under process-like conditions, solutions of $\mathrm{CyMe}_{4}{ }^{-}$ BTBP 107 and tributyl phosphate 1 (used in the PUREX process) in cyclohexanone selectively extracted $\mathrm{Am}, \mathrm{Pu}, \mathrm{Np}$ and $\mathrm{U}$ from $4 \mathrm{M}$ nitric acid solutions of high metal loading (> $9000 \mathrm{ppm}$ ), ${ }^{107}$ suggesting that a GANEX process is feasible. It was shown that each ligand extracted independently of the other and no synergistic effects were observed.
Recently, the first crystal structures of actinide complexes of $\mathrm{CyMe}_{4}-\mathrm{BTBP} \mathbf{1 0 7}$ have been reported. Treatment of the ligand with the uranyl salts $\mathrm{UO}_{2}(\mathrm{OTf})_{2}$ and $\mathrm{UO}_{2} \mathrm{I}_{2}(\mathrm{THF})_{3}$ under anhydrous conditions led to the formation of mononuclear 1:1 complexes in which the ligand coordinates to the metal in a tetradentate fashion perpendicular to the plane of the $\mathrm{UO}_{2}{ }^{2+}$ ion. ${ }^{108}$ In the presence of moist air, the complexes crystallized as the dinuclear complexes $\left[\left(\mathrm{UO}_{2} \mathrm{~L}\right)-\mathrm{O}-\left(\mathrm{UO}_{2} \mathrm{~L}\right)^{2+}\right]$ containing a flexible $\mu$-oxo bridge. Mononuclear 1:1 complexes of $\mathbf{1 0 7}$ were also obtained with tetravalent $\mathrm{Cp}_{2}{ }_{2} \mathrm{U}^{2+}$ ions, and with pentavalent $\mathrm{UO}_{2}{ }^{+}$ions which were formed by reduction of the corresponding $\mathrm{UO}_{2}{ }^{2+}$ complexes with $\mathrm{KC}_{5} \mathrm{Me}_{5}$ or $\mathrm{TlC}_{5} \mathrm{H}_{5}{ }^{109} \mathrm{~A}$ very unusual dinuclear $\mu$-oxo mixed valence $\mathrm{U}(\mathrm{IV}) / \mathrm{U}(\mathrm{VI})$ complex was isolated from a mixture of $\mathrm{U}(\mathrm{OTf})_{4}, \mathrm{UO}_{2}\left(\mathrm{NO}_{3}\right)_{2}$ and $\mathrm{CyMe}_{4}-$ BTBP 107. ${ }^{77}$ In this complex, two ligands $\mathbf{1 0 7}$ coordinate to the $\mathrm{U}(\mathrm{IV})$ ion in an orthogonal arrangement while the nitrates coordinate to the U(VI) ion.

A comparative investigation of the complexation of $\mathrm{Cm}$ (III) and $\mathrm{Eu}$ (III) by ${ }^{\mathrm{t}} \mathrm{Bu}-\mathrm{C} 2-\mathrm{BTBP} 103$ using timeresolved laser-induced fluorescence spectroscopy (TRLFS) was carried out under conditions relevant to the extraction process. Complexes of 1:2 stoichiometry were observed for both metal ions but the stability constant for the $\mathrm{Cm}$ (III) complex was found to be approx. two orders of magnitude higher than that for the Eu(III) complex. ${ }^{110}$ The enthalpy of complexation of $\mathrm{Cm}$ (III) was more negative than that of Eu(III), while the entropy of complexation of both metal ions was very similar. This study showed that the remarkably high selectivity of the BTBPs for An(III) over Ln(III) was driven by the greater thermodynamic stability of its complexes with An(III).

Recent quantum mechanics calculations show that the BTBPs are less basic, and afford complexes that are less thermodynamically stable than those of their rigidified phenanthroline (BTPhen) analogues. Molecular dynamics simulations at the oil/water interface reveal that $\mathrm{CyMe}_{4}-\mathrm{BTBP} \mathbf{1 0 7}$ is only surface active when protonated, and when complexed to a single Eu(III) cation. ${ }^{111}$ As with the BTPs, the $\mathrm{NH}^{+}$ group of the protonated BTBP ligand 107 orients away from the aqueous phase to avoid hydrophobic contacts with the aliphatic rings. These results suggest that the extraction of Am(III) and Eu(III) by 107 takes place at the interface via the protonated ligand in acidic conditions, and explains why the extraction kinetics is slow in the absence of a phase transfer agent.

In an effort to better understand the origins of the high selectivity of bis-triazine ligands for An over Ln, we investigated the pentadentate ligand $\mathrm{CyMe}_{4}-\mathrm{BTTP}$ 109, which contains an additional pyridine ring compared to the BTBPs. Although mildly selective $\left(\mathrm{SF}_{\mathrm{Am} / \mathrm{Eu}} \leq 12\right)$, the ligand was essentially unable to 
extract $\mathrm{Am}(\mathrm{III})$ or $\mathrm{Eu}(\mathrm{III})$ from $\mathrm{HNO}_{3}$ into 1-octanol in the absence of a synergist $\left(D_{\mathrm{Am}}<0.04\right)$, making it less efficient than the tetradentate $\mathrm{CyMe}_{4}-\mathrm{BTBP} \mathbf{1 0 7}$ by about two orders of magnitude. ${ }^{112}$ In nitrate media, only the 1:1 complexes with $\mathrm{Ln}(\mathrm{III})$ were observed by NMR and mass spectrometry, whereas the more hydrophobic 1:2 complexes were formed in perchlorate media, indicating that nitrate ions competed with the ligand $\mathbf{1 0 9}$ for coordination sites on the metal resulting in less hydrophobic 1:1 complexes which were not easily extracted.

\section{Improving Radiolytic Stability through Ligand Design}

In a potential SANEX process the organic and aqueous phases will be exposed to high levels of ionizing radiation due to the presence of radioactive $\alpha$ and $\gamma$-emitting radionuclides. This will impact the performance of any solvent extraction processes used for nuclear fuel reprocessing, and a knowledge of these effects is critical for the design of robust solvent systems. The effect of radiation chemistry on solvent extraction processes was recently reviewed. ${ }^{113}$ It has been estimated that the organic phase in a SANEX process will receive a total annual dose of between $100 \mathrm{kGy}$ and $1 \mathrm{MGy}$, depending on the type of waste being reprocessed. ${ }^{84}$ Direct absorption of this energy by the diluent molecules of the organic and aqueous phases leads to the formation of electronically excited states, free-radical species, solvated electrons and ions which can subsequently react with the extractant molecules.

The radiolysis of water can be represented by the equation: ${ }^{114}$

$\mathrm{H}_{2} \mathrm{O}^{*} \rightarrow \bullet \mathrm{OH}+\mathrm{H}^{\bullet}+\mathrm{e}^{-}+\mathrm{H}_{2} \mathrm{O}_{2}+\mathrm{H}_{3} \mathrm{O}^{+}+\mathrm{H}_{2}$

while for a typical alkane-like organic diluent, the radiolysis can be represented by: ${ }^{115}$

$\mathrm{CH}_{3}\left(\mathrm{CH}_{2}\right)_{\mathrm{n}} \mathrm{CH}_{3}{ }^{*} \rightarrow \mathrm{CH}_{3}\left(\mathrm{CH}_{2}\right)_{\mathrm{n}} \mathrm{CH}_{3}{ }^{\bullet+}+\mathrm{e}^{-}+$ $\mathrm{CH}_{3}\left(\mathrm{CH}_{2}\right)_{\mathrm{n}} \mathrm{CH}_{2}{ }^{\bullet}+{ }^{\bullet} \mathrm{CH}_{3}+\mathrm{H}^{\bullet}+\mathrm{H}_{2}$

Process development studies on the dialkyl-BTPs such as diisopropyl-BTP 71 showed that the ligands were susceptible to indirect radiolysis caused by chemical attack at their reactive benzylic positions by freeradical species, with detrimental effects on their extraction ability and selectivity. ${ }^{83 \mathrm{~b}}$ Furthermore, the extraction performance of dipentyl-BTBP $\mathbf{1 0 5}$ decreased with increasing doses of $\gamma$-radiation, and the likely degradation products were identified by mass spectrometry. ${ }^{116}$ Many of the degradation products arose from hydrogen atom abstraction and subsequent oxidation of the benzylic positions eventually leading to cleavage of the alkyl groups. The replacement of the labile benzylic hydrogens with alkyl groups thus became the primary goal in the design and synthesis of selective actinide extractants with improved resistance to radiolysis.
Subsequently, attempts were made to synthesize a BTP ligand containing tert-butyl groups attached to the triazine rings, rather than primary alkyl groups. Unfortunately, the condensation reaction of pivalil with pyridine-2,6-dicarboxamide hydrazone (Scheme 6 where $\mathrm{R}={ }^{\mathrm{t}} \mathrm{Bu}$ ) failed to afford the desired ligand, probably due to the sterically hindered nature of the $\alpha$ diketone or its inability to adopt the cis-conformation required for the condensation reaction. It was reasoned that a cyclic $\alpha$-diketone would be more reactive as the carbonyl groups would be locked in the required cis-conformation. Gratifyingly, the reaction of pyridine-2,6-dicarboxamide hydrazone with the cyclic $\alpha$-diketones 3,3,6,6-tetramethylcyclohexane1,2-dione and 1,1',4,4'-tetramethylnaphthalene-2,3dione furnished in high yields the annulated ligands $\mathrm{CyMe}_{4}$-BTP 74 and $\mathrm{BzCyMe}_{4}$-BTP 75, respectively (Table 6). ${ }^{117}$

In solvent extraction experiments, $\mathrm{CyMe}_{4}$-BTP $\mathbf{7 4}$ proved to be a more effective extractant than diisopropyl-BTP $\mathbf{7 1}$ in the presence of the phasemodifier DMDOHEMA. Typically, for $0.01 \mathrm{M}$ solutions of the ligands in 1-octanol after 15 minutes of phase contact with $0.5 \mathrm{M} \mathrm{HNO}_{3}, D_{\mathrm{Am}}=$ ca. 500 and $\mathrm{SF}_{\mathrm{Am} / \mathrm{Eu}}=$ ca. 5000 for $\mathrm{CyMe}_{4}$-BTP 74 whereas $D_{\mathrm{Am}}=$ ca. 30 and $\mathrm{SF}_{\mathrm{Am} / \mathrm{Eu}}=$ ca. 400 for diisopropyl-BTP 71 . For BzCyMe ${ }_{4}$-BTP 75, $D_{\text {Am }}=$ ca. 10 and $\mathrm{SF}_{\mathrm{Am} / \mathrm{Eu}}=\mathrm{ca}$. 500 under identical conditions. ${ }^{117}$ The remarkably high selectivity for $\mathrm{Am}(\mathrm{III})$ over $\mathrm{Eu}(\mathrm{III})$ of $\mathrm{CyMe}_{4}$ BTP 74 was far in excess of what was observed with other $N$-donor ligands. The formation of the expected 1:3 complexes of $\mathbf{7 4}$ with the lanthanides was confirmed by ${ }^{1} \mathrm{H}$ NMR titrations and X-ray crystallography.

In contrast to other BTPs, both of the annulated BTPs 74 and 75 were stable to hydrolysis and were not hydrolyzed by boiling nitric acid ( $3 \mathrm{M}$ ) over 24 hours. After exposure of 1-octanol solutions of the ligands to $100 \mathrm{kGy}$ of $\gamma$-radiation, there was significant degradation of $\mathrm{CyMe}_{4}$-BTP $\mathbf{7 4}$ and diisopropyl-BTP 71 (ca. $80 \%$ ), but no degradation of $\mathrm{BzCyMe}_{4}$-BTP 75 occurred. It is thought that the additional aromatic rings present in $\mathbf{7 5}$ compared to $\mathbf{7 4}$ are able to dissipate some of the energy absorbed by the ligand during direct radiolysis. Theoretical simulations of electron loss and gain on various fragments of $\mathbf{7 4}$ and 75 suggest that, upon electron loss (as would occur during direct radiolysis), most of the charge resides in the benzene rings of $75(64 \%)$ but in the triazine rings of $74(45 \%)$. This view is supported by frontier orbital calculations which show that there are two pairs of doubly-degenerate HOMOs localized on the outer benzene rings of $\mathbf{7 5}$ which are not present in 74. $^{117}$

The stability of the tetradentate ligands $\mathrm{CyMe}_{4}$-BTBP $\mathbf{1 0 7}$ and its more soluble ${ }^{118}$ derivative MF2-BTBP 108 towards radiolysis was then investigated. When exposed to low doses of gamma irradiation $(<30$ $\mathrm{kGy}), \mathrm{CyMe}_{4}$-BTBP $\mathbf{1 0 7}$ dissolved in hexanol or 
cyclohexanone showed good stability and the extraction of $\mathrm{Am}(\mathrm{III})$ and $\mathrm{Eu}(\mathrm{III})$ remained largely unaffected. In contrast, the extraction efficiency of dipentyl-BTBP 105, which has benzylic hydrogens, decreased as the total absorbed dose increased under the same conditions. ${ }^{119}$ However, the resistance of MF2-BTBP 108 dissolved in cyclohexanone towards gamma radiolysis was found to depend on the dose rate. At low dose rates (ca. $15 \mathrm{~Gy} / \mathrm{h}$ ), the extraction of $\mathrm{Am}$ (III) and Eu(III) by MF2-BTBP 108 was more or less unchanged up to an absorbed dose of $100 \mathrm{kGy}$ but at high dose rates (ca. $1.2 \mathrm{kGy} / \mathrm{h}$ ), the extraction of $\mathrm{Am}$ (III) and $\mathrm{Eu}(\mathrm{III})$ decreased with increasing dose, indicating that secondary processes (indirect radiolysis) were likely to be responsible for the degradation rather than the radiation directly. ${ }^{120}$ In a similar study, CyMe $\mathrm{C}_{4}$-BTBP 107 in 1-octanol was more sensitive to gamma radiolysis $(0.22 \mathrm{kGy} / \mathrm{h})$ than to alpha radiolysis $(1 \mathrm{kGy} / \mathrm{h})$, and the rate of degradation of $\mathbf{1 0 7}$ was $40 \%$ higher when exposed to gamma radiation. ${ }^{121}$

One of the drawbacks of $\mathrm{CyMe}_{4}-\mathrm{BTP} 74, \mathrm{CyMe}_{4}{ }^{-}$ BTBP 107 and MF2-BTBP 108 is the difficulties encountered in synthesizing large quantities of the ligands for process development studies. This is due to the relatively inefficient method of synthesizing the $\alpha$ diketone precursor (Scheme 9). The first step involves the generation of 2,2,5,5-tetramethyladipic acid by the free-radical dimerization of pivalic acid mediated by Fenton's reagent $\left(\mathrm{H}_{2} \mathrm{O}_{2}\right.$ and $\left.\mathrm{FeSO}_{4}\right){ }^{122}$ This reaction is reported to give yields of ca. $37 \%$ but in our hands, yields of $15 \%$ or lower were obtained. The diacid is then esterified and the diester is cyclized by an intramolecular acyloin reaction using sodium and chlorotrimethylsilane in toluene. Oxidation of the enediolate bis-silyl ether with bromine then affords 3,3,6,6-tetramethylcyclohexane-1,2-dione. The acyloin reaction may also be carried out in the absence of chlorotrimethylsilane generating the $\alpha$ hydroxyketone which is then oxidised to the $\alpha$ diketone using copper(II) acetate. ${ }^{123}$

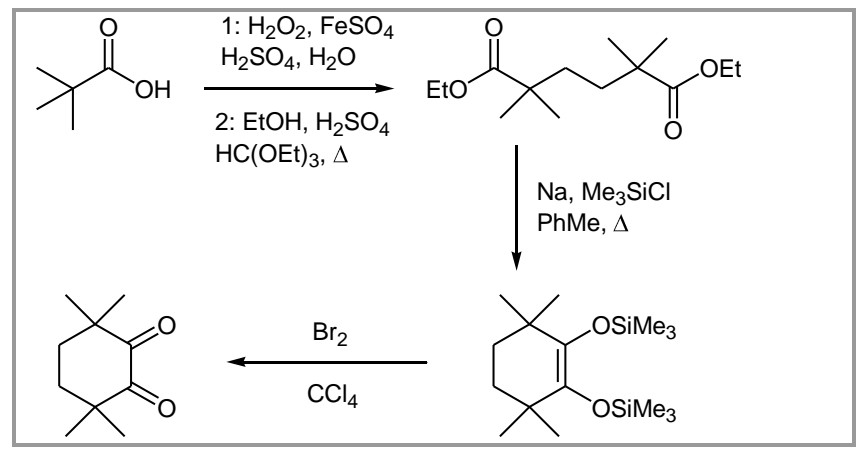

Scheme 9 Synthesis of 3,3,6,6-tetramethylcyclohexane-1,2-dione

Although suitable for synthesizing small quantities of $\mathbf{7 4 ,} \mathbf{1 0 7}$ and $\mathbf{1 0 8}$, this synthetic route is impractical for large-scale synthesis and thus presents a barrier to the application of the ligands in an industrial SANEX process. Recently, a new and more efficient synthesis of 3,3,6,6-tetramethylcyclohexane-1,2-dione was developed (Scheme 10) which by-passes the problematic first step in the previous method. ${ }^{124}$ Alkylation of the enolate of ethyl isobutyrate with 1,2disulfonate esters derived from ethylene glycol afforded the diester intermediate in good yields (69$70 \%)$

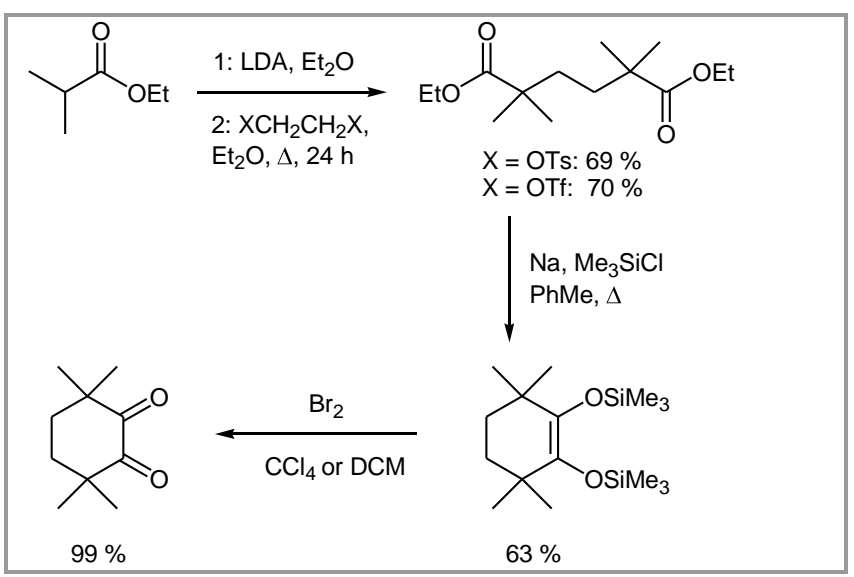

Scheme 10 Modified and improved synthesis of 3,3,6,6tetramethylcyclohexane-1,2-dione

Interestingly, when this reaction was conducted using softer 1,2-dihalides as electrophiles, mixtures of products were obtained of which the major product was the corresponding ethyl $\alpha$-haloisobutyrate. This product was formed by attack of the enolate on the halogen atom with subsequent elimination of ethylene. ${ }^{125}$ Completion of the synthesis as before (intramolecular acyloin reaction/oxidation) yielded the a-diketone with significantly higher yields than the previous method (44\% overall compared to $<5 \%$ overall). This facile synthesis of the diketone precursor to $\mathrm{CyMe}_{4}$-based ligands such as 74, 107 and 108 removed one of the biggest obstacles to the development of an industrial SANEX process, namely, the ability to synthesize the ligands on a large scale.

\section{Conclusions and Outlook}

In summary, we have surveyed recent advances in Europe in the design, synthesis, study and development of soft $\mathrm{N}$ - and S-donor ligands for separating actinides from lanthanides in the nuclear fuel cycle. Bis-1,2,4-triazine ligands composed only of the elements $\mathrm{C}, \mathrm{H}, \mathrm{O}$ and $\mathrm{N}$ have emerged as the most promising family of ligands for this purpose, showing levels of selectivity between the chemically similar actinides and lanthanides once thought impossible to achieve. These reagents and their extracted metal complexes possess a high enough range of solubilities in suitable diluents such as 1octanol for use in the SANEX process. Optimum levels of affinity that permit back-extraction of the 
metals have been achieved with the BTBP ligands. The BTBPs are not susceptible to hydrolysis and are resistant to radiolysis at low dose rates. The ease of synthesis of these reagents has been recently improved, and $\mathrm{CyMe}_{4}$-BTBP $\mathbf{1 0 7}$ is now commercially available. Furthermore, the ligands are capable of extracting from solutions of high acidity.

\section{Acknowledgment}

We are grateful to the Nuclear Fission Safety Program of the European Union for support under the ACSEPT (FP7-CP2007-211 267) contract.

\section{References}

(1) (a) World Energy Outlook, International Atomic Energy Agency (IAE/OECD), 2007. (b) Nuclear Energy Outlook 2008, OECD/NEA, Paris, 2008.

(2) Implications of partitioning and transmutation in radioactive waste management, International Atomic Energy Agency, Technical Report Series, no. 435, Vienna, 2004.

(3) (a) McKibben, J. M. Radiochim. Acta 1984, 36, 3. (b) Sood, D. D.; Patil, S. K. J. Rad. Nucl. Chem. 1996, 203, 547. (c) Musikas, C .; Schultz, W.; Liljenzin, J.-O. in Solvent Extraction Principles and Practice, 2nd ed; Rydberg, J.; Cox, M.; Musikas, C.; Choppin, G.., Eds.; Marcel Dekker, Inc.: New York, 2004, pp 507-557. (d) Nash, K. L.; Madic, C.; Mathur, J.; Lacquement, J. in The Chemistry of the Actinide and Transactinide Elements, 3rd ed; Katz, J. J.; Morss, L. R.; Edelstein, N. M.; Fuger, J., Eds.; Springer: Dordrecht, 2006, pp 26222798.

(4) Magill, J.; Berthou, V.; Haas, D.; Galy, J.; Schenkel, R.; Wiese, H.-W.; Heusener, G.; Tommasi, J.; Youinou, G. Nuclear Energy 2003, 42, 263.

(5) (a) Actinide and fission product partitioning and transmutation status and assessment report, OECD/NEA, Paris, 1999. (b) Salvatores, M.; Nucl. Eng. Design 2005, 235, 805. (c) Salvatores, M.; Palmiotti, G. Progress in Particle and Nuclear Physics 2011, 66, 144.

(6) (a) Nash, K. L. Solvent Extr. Ion Exch. 1993, 11, 729. (b) Mathur, J. N.; Murali, M. S.; Nash, K. L. Solvent Extr. Ion Exch. 2001, 19, 357.

(7) (a) Cuillerdier, C.; Musikas, C. Sep. Sci. Technol. 1991, 26, 1229. (b) Modolo, G.; Vijgen, H.; Serrano-Purroy, D.; Christiansen, B.; Malmbeck, R.; Sorel, C.; Baron, P. Sep. Sci. Technol. 2007, 42, 439.

(8) Horwitz, E. P.; Kalina, D. G.; Diamond, H.; Vandegrift, G. F.; Schulz, W. W. Solvent Extr. Ion Exch. 1985, 3, 75.

(9) (a) Cuillerdier, C.; Musikas, C.; Hoel, P.; Nigond, L.; Vitart, X. Sep. Sci. Technol. 1991, 26, 1229. (b) Nigond, L.; Condamines, N.; Cordier, P. Y.; Livet, J.; Madic, C.; Cuillerdier, C.; Musikas, C.; Hudson, M. J. Sep. Sci. Technol. 1995, 30, 2075.

(10) Chan, G. Y. S.; Drew, M. G. B.; Hudson, M. J.; Iveson, P. B.; Liljenzin. J.-O.; Skålberg, M.; Spjuth, L.; Madic, C. J. Chem. Soc. Dalton Trans. 1997, 649.

(11) Serrano-Purroy, D.; Baron, P.; Christiansen, B.; Malmbeck, R.; Sorel, C.; Glatz, J.-P. Radiochim. Acta 2005, 93, 351.

(12) (a) Modolo, G.; Asp. H.; Schreinemachers, C.; Vijgen, H. Solvent Extr. Ion Exch. 2007, 25, 703. (b) Magnusson, D.; Christiansen, B.; Glatz, J.-P.; Malmbeck, R.; Modolo, G.; Serrano-Purroy, D.; Sorel, C. Solvent Extr. Ion Exch. 2009, 27, 26.
The considerable advances of recent years, both in process demonstrations as well as in molecular-level understanding, set the stage for the development of even more efficient and robust ligands for use in more demanding future actinide/lanthanide separation processes (eg: GANEX process).

(13) (a) Cotton, S. in Comprehensive Coordination Chemistry II, Vol. 3; McCleverty, J. A.; Meyer, T. J., Eds.; Elsevier: Oxford, 2004, pp 93-188. (b) Burns, C. J.; Neu, M. P.; Boukhalfa, H.; Gutowski, K. E.; Bridges, N. J.; Rogers, R. D. in Comprehensive Coordination Chemistry II, Vol. 3; McCleverty, J. A.; Meyer, T. J., Eds.; Elsevier: Oxford, 2004, pp 189-332. (c) Katz, J. J.; Morss, L. R.; Edelstein, N. M.; Fuger, J. in The Chemistry of the Actinide and Transactinide Elements, Vol. 1; Katz, J. J.; Morss, L. R.; Edelstein, N. M.; Fuger, J., Eds.; Springer: Dordrecht, 2006, pp 1-17.

(14) Nilsson, M.; Nash, K. L. Solvent Extr. Ion Exch. 2007, 25,665 .

(15) Hudson, M. J.; Czech. J. Phys. 2003, 53, A305.

(16) (a) Dam, H. H.; Reinhoudt, D. N.; Verboom, W. Chem. Soc. Rev. 2007, 36, 367. (b) Ekberg, C.; Fermvik, A.; Retegan, T.; Skarnemark, G.; Foreman, M. R. S.; Hudson, M. J.; Englund, S.; Nilsson, M. Radiochim. Acta 2008, 96, 225. (c) Kolarik, Z. Chem. Rev. 2008, 108, 4208. (d) Hill, C. in Ion Exchange and Solvent Extraction: A Series of Advances, Vol. 19; Moyer, B. A., Ed.; CRC Press: Boca Raton, 2010, pp 119-194.

(17) (a) Zhu, Y. Radiochim. Acta 1995, 68, 95. (b) Zhu, Y; Chen. J.; Jiao, R. Solvent Extr. Ion Exch. 1996, 14, 61. (c) Chen. J.; Zhu, Y.; Jiao, R. Sep. Sci. Technol. 1996, 31, 2723. (d) Hill, C.; Madic, C.; Baron. P.; Ozawa, M.; Tanaka, Y. J. Alloys Compd. 1998, 271-273, 159. (e) Wang, X.; Zhu, Y.; Jiao, R. J. Rad. Nucl. Chem. 2002 $251,487$.

(18) Ionova, G.; Ionov, S.; Rabbe, C.; Hill, C.; Madic, C.; Guillaumont, R.; Krupa, J. C. Solvent Extr. Ion Exch. 2001, 19, 391.

(19) (a) Bhattacharyya, A.; Mohapatra, P. K.; Manchanda, V. K. Solvent Extr. Ion Exch. 2006, 24, 1. (b) Bhattacharyya, A.; Mohapatra, P. K.; Manchanda, V. K. Radiochim. Acta 2010, 98, 141.

(20) (a) Peterman, D. R.; Law, J. D.; Todd, T. A.; Tillotson, R. D. in Separations for the Nuclear Fuel Cycle in the 21 st Century, Vol 933; Lumetta, G. J.; Nash, K. L.; Clark, S. B.; Friese, J. I., Eds.; American Chemical Society: Washington DC, 2006, pp 251-259. (b) Law, J. D.; Peterman, D. R.; Todd, T. A.; Tillotson, R. D. Radiochim. Acta 2006, 94, 261.

(21) (a) Wei, Y.; Kumagai, M.; Takashima, Y.; Modolo, G.; Odoj, R. Nuclear Technology 2000, 132, 413. (b) Bhattacharyya, A.; Mohapatra, P. K.; Manchanda, V. K. J. Chromatography A 2006, 1123, 26. (c) Bhattacharyya, A.; Mohapatra, P. K.; Manchanda, V. K. Solvent Extr. Ion Exch. 2007, 25, 27.

(22) Mimura, H.; Hoshi, H.; Akiba, K.; Onodera, Y. J. Rad. Nucl. Chem. 2001, 247, 375.

(23) Hoshi, H.; Tsuyoshi, A.; Akiba, K. J. Rad. Nucl. Chem. 2000, 243, 621

(24) Wang, X.; Zhu, Y.; Jiao, R. Solvent Extr. Ion Exch. 2001, 19, 1007.

(25) Modolo, G.; Odoj, R. J. Rad. Nucl. Chem. 1998, 228, 83.

(26) (a) Modolo, G.; Odoj, R. J. Alloys Compd. 1998, 271273, 248. (b) Modolo, G.; Odoj, R. US5966584 (1999). (c) Geist, A.; Weigl, M.; Gompper, K. Sep. Sci. Technol. 
2002, 37, 3369 .

(27) Modolo, G; Odoj, R. Solvent Extr. Ion Exch. 1999, 17, 33.

(28) Modolo, G.; Seekamp, S. Solvent Extr. Ion Exch. 2002, $20,195$.

(29) (a) Modolo, G.; Nabet, S. Solvent Extr. Ion Exch. 2005, 23, 359. (b) Modolo, G.; Odoj, R. US20070009410A1 (2007).

(30) Modolo, G.; Kluxen, P. Geist, A. Radiochim. Acta 2010, 98, 193.

(31) Ionova, G.; Ionov, S.; Rabbe, C.; Hill, C.; Madic, C.; Guillaumont, R.; Modolo, G.; Krupa, J. C. New J. Chem. 2001, 25, 491.

(32) (a) Klaehn, J. R.; Peterman, D. R.; Harrup, M. K.; Tillotson, R. D.; Luther, T. A.; Law, J. D.; Daniels, L. M. Inorg. Chim. Acta 2008, 361, 2522. (b) Peterman, D. R.; Greenhalgh, M. R.; Tillotson, R. D.; Klaehn, J. R.; Harrup, M. K.; Luther, T. A.; Law, J. D. Sep. Sci. Technol. 2010, 45, 1711 .

(33) Qichu, X.; Jianfeng, W.; Yinzhong, C.; Lixing, Z.; Yusheng, Y. Radiochim. Acta 2008, 96, 771.

(34) Weigl, M.; Denecke, M. A.; Panak, P. J.; Geist, A.; Gompper, K. Dalton Trans. 2005, 1281.

(35) Coupez, B.; Boehme, C.; Wipff, G. J. Phys. Chem. B 2003, 107, 9484.

(36) Cordier, P. Y.; Hill, C.; Baron, P.; Madic, C.; Hudson, M. J.; Liljenzin, J.-O. J. Alloys Compd. 1998, 271-273, 738.

(37) Hagström, I.; Spjuth, L.; Enarsson, Å.; Liljenzin, J.-O.; Skålberg, M.; Hudson, M. J.; Iveson, P. B.; Madic, C.; Cordier, P. Y.; Hill, C.; Francois, N. Solvent Extr. Ion Exch. 1999, 17, 221.

(38) Drew, M. G. B.; Iveson, P. B.; Hudson, M. J.; Liljenzin, J.-O.; Spjuth, L.; Cordier, P. Y.; Enarsson, Å.; Hill, C.; Madic, C. J. Chem. Soc. Dalton Trans. 2000, 821.

(39) Grigoriev, M. S.; Den Auwer, C.; Madic, C. Acta Cryst. 2001, C57, 1141.

(40) Berthet, J.-C.; Rivière, C.; Miquel, Y.; Nierlich, M.; Madic, C.; Ephritikhine, M. Eur. J. Inorg. Chem. 2002, 1439.

(41) Drew, M. G. B.; Hudson, M. J.; Iveson, P. B.; Russell, M. L.; Liljenzin, J.-O.; Skålberg, M.; Spjuth, L.; Madic, C. J. Chem. Soc. Dalton Trans. 1998, 2973

(42) (a) Case, F. H.; Koft, E. J. Am. Chem. Soc. 1959, 81, 905. (b) Forsberg, J. H.; Spaziano, V. T.; Klump, S. P.; Sanders, K. M. J. Het. Chem. 1988, 25, 767. (c) Hudson, M. J.; Chan, G. Y. S.; Madic, C.; Baron. P. GB2296917A (1996). (d) Drew. M. G. B.; Hudson, M. J.; Iveson, P. B.; Russell, M. L.; Madic, C. Acta Cryst. 1998, C54, 985.

(43) (a) Chan, G. Y. S.; Drew, M. G. B.; Hudson, M. J.; Isaacs, N. S.; Byers, P. Polyhedron 1996, 15, 3385. (b) Drew, M. G. B.; Hudson, M. J.; Iveson, P. B.; Madic, C. Acta Cryst. 2000, C56, 434.

(44) (a) Musikas, C. Actinide-Lanthanide Group Separation Using Sulfur and Nitrogen Donor Extractants. Proceedings of the International Symposium on Actinide/Lanthanide Separations, Honolulu, Hawaii, USA (1984). (b) Madic, C.; Hudson, M. J. High-Level Liquid Waste Partitioning by Means of Completely Incinerable Extractants. Final Report, European Commission contract No. F12W-CT91-0112, EUR18038 (1998).

(45) Drew, M. G. B.; Hudson, M. J.; Iveson, P. B.; Madic, C.; Russell, M. L. J. Chem. Soc. Dalton Trans. 2000, 2711.

(46) Boubals, N.; Drew, M. G. B.; Hill, C.; Hudson, M. J.; Iveson, P. B.; Madic, C.; Russell, M. L.; Youngs, T. G. A. J. Chem. Soc. Dalton Trans. 2002, 55.

(47) Miguirditchian, M.; Guillaneux, D.; Guillaumont, D.; Moisy, P.; Madic, C.; Jensen, M. P.; Nash, K. L. Inorg.
Chem. 2005, 44, 1404.

(48) Addison, A. W.; Burke, P. J. J. Het. Chem. 1981, 18, 803.

(49) Drew, M. G. B.; Hill, C.; Hudson, M. J.; Iveson, P. B.; Madic, C.; Vaillant, L.; Youngs, T. G. A. New J. Chem. 2004, 28, 462 .

(50) (a) Andersson, S.; Ekberg, C.; Foreman, M. R. S.; Hudson, M. J.; Liljenzin, J.-O.; Nilsson, M.; Skarnemark, G.; Spahiu, K. Solvent Extr. Ion Exch. 2003, 21, 621. (b) Andersson, S.; Ekberg, C.; Liljenzin, J.-O.; Nilsson, M.; Skarnemark, G. Radiochim. Acta 2004, 92, 863.

(51) Wietzke, R.; Mazzanti, M.; Latour, J.-M.; Pécaut, J. ; Cordier, P.-Y. ; Madic, C. Inorg. Chem. 1998, 37, 6690.

(52) Ishimori, K.; Watanabe, M.; Kimura, T.; Yaita, T.; Yamada, T.; Kataoka, Y.; Shinoda, S. ; Tsukube, H. Chem. Lett. 2005, 34, 1112.

(53) Wietzke, R.; Mazzanti, M.; Latour, J.-M.; Pécaut, J. J. Chem. Soc. Dalton Trans. 2000, 4167.

(54) Natrajan, L. ; Pécaut, J. ; Mazzanti, M. ; LeBrun, C. Inorg. Chem. 2005, 44, 4756.

(55) Bravard, F. ; Rosset, C. ; Delangle, P. Dalton Trans. 2004, 2012.

(56) Denecke, M. A. ; Panak, P. J.; Burdet, F.; Weigl, M.; Geist, A.; Klenze, R.; Mazzanti, M.; Gompper, K. C. $R$. Chimie 2007, 10, 872.

(57) (a) Watanabe, M.; Mirvaliev, R.; Tachimori, S.; Takeshita, K.; Nakano, Y.; Morikawa, K.; Mori, R. Chem. Lett. 2002, 31, 1230. (b) Mirvaliev, R.; Watanabe, M.; Matsumura, T.; Tachimori, S.; Takeshita, K. J. Nucl. Sci. Technol. 2004, 41, 1122.

(58) Matsumura, T.; Takeshita, K. in Separations for the Nuclear Fuel Cycle in the 21st Century, Vol 933; Lumetta, G. J.; Nash, K. L.; Clark, S. B.; Friese, J. I., Eds.; American Chemical Society: Washington DC, 2006, pp 261-273.

(59) Karmazin, L.; Mazzanti, M.; Gateau, C.; Hill, C.; Pécaut, J. Chem. Commun. 2002, 2892.

(60) (a) Wibaut, J. P.; de Jonge, A. P.; van der Voort, H. G. P.; Otto, P. Ph. H. L. Rec. Trav. Chim. Pays-Bas 1951, 70, 1054. (b) Hannon, M. J.; Mayers, P. C.; Taylor, P. C. Tetrahedron Lett. 1998, 39, 8509. (c) Jonas, R. T.; Stack, T. D. P. Inorg. Chem. 1998, 37, 6615.

(61) Ishimori, K.; Watanabe, M.; Kimura, T.; Murata, M.; Nishihara, H. J. Alloys Compd. 2006, 408-412, 1278.

(62) Watanabe, M.; Nankawa, T.; Yamada, T.; Kimura, T.; Namiki, K.; Murata, M.; Nishihara, H.; Tachimori, S. Inorg. Chem. 2003, 42, 6977.

(63) Case, F. H. J. Het. Chem. 1971, 8, 1043.

(64) (a) Pabst, G. R.; Sauer, J. Tetrahedron Lett. 1998, 39, 6687. (b) Sauer, J. ; Heldmann, D. K.; Pabst, G. R. Eur. J. Org. Chem. 1999, 313. (c) Pabst, G. R.; Pfüller, O. C.; Sauer, J. Tetrahedron 1999, 55, 5047. (d) Pabst, G. R.; Sauer, J. Tetrahedron 1999, 55, 5067.

(65) Kolarik, Z.; Müllich, U.; Gassner, F. Solvent Extr. Ion Exch. 1999, 17, 23.

(66) Weigl, M.; Müllich, U.; Geist, A.; Gompper, K.; Zevaco, T.; Stephan, H. J. Rad. Nucl. Chem. 2003, 256, 403.

(67) Kolarik, Z.; Müllich, U.; Gassner, F. Solvent Extr. Ion Exch. 1999, 17, 1155.

(68) Weigl, M.; Geist, A.; Müllich, U.; Gompper, K. Solvent Extr. Ion Exch. 2006, 24, 845.

(69) Drew, M. G. B.; Guillaneux, D.; Hudson, M. J.; Iveson, P. B. ; Madic, C. Inorg. Chem. Commun. 2001, 4, 462.

(70) Boucher, C.; Drew, M. G. B.; Giddings, P.; Harwood, L. M.; Hudson, M. J.; Iveson, P. B.; Madic, C. Inorg. Chem. Commun. 2002, 5, 596.

(71) Drew, M. G. B.; Hudson, M. J.; Iveson, P. B.; Madic, C.; Russell, M. L. J. Chem. Soc. Dalton Trans. 1999, 2433. 
(72) Drew, M. G. B.; Guillaneux, D.; Hudson, M. J.; Iveson, P. B. ; Russell, M. L. ; Madic, C. Inorg. Chem. Commun. 2001, 4,12 .

(73) (a) Iveson, P. B.; Rivière, C.; Guillaneux, D. ; Nierlich, M. ; Thuéry, P. ; Ephritikhine, M. ; Madic, C. Chem. Commun. 2001, 1512. (b) Berthet, J.-C.; Miquel, Y.; Iveson, P. B.; Nierlich, M.; Thuéry, P.; Madic, C.; Ephritikhine, M. J. Chem. Soc. Dalton Trans. 2002, 3265.

(74) Benay, G.; Schurhammer, R.; Desaphy, J.; Wipff, G. New J. Chem. 2011, 35, 184.

(75) (a) Colette, S.; Amekraz, B.; Madic, C. ; Berthon, L. ; Cote, G. ; Moulin, C. Inorg. Chem. 2002, 41, 7031. (b) Colette, S.; Amekraz, B.; Madic, C. ; Berthon, L. ; Cote, G. ; Moulin, C. Inorg. Chem. 2003, 42, 2215. (c) Colette, S.; Amekraz, B.; Madic, C. ; Berthon, L. ; Cote, G. ; Moulin, C. Inorg. Chem. 2004, 43, 6745. (d) Steppert, M.; Walther, C.; Geist, A.; Fanghänel, T. New J. Chem. 2009, 33, 2437.

(76) (a) Denecke, M. A.; Rossberg, A.; Panak, P. J.; Weigl, M.; Schimmelpfennig, B.; Geist, A. Inorg. Chem. 2005, 44, 8418. (b) Miguirditchian, M.; Guillaneux, D.; Francois, N.; Airvault, S.; Ducros, S.; Thauvin, D.; Madic, C.; Illemassène, M.; Lagarde, G.; Krupa, J.-C. Nucl. Sci. Eng. 2006, 153, 223. (c) Trumm, S.; Panak, P. J.; Geist, A.; Fanghänel, T. Eur. J. Inorg. Chem. 2010, 3022. (d) Banik, N. L.; Schimmelpfennig, B.; Marquardt, C. M.; Brendebach, B.; Geist, A.; Denecke, M. A. Dalton Trans. 2010, 39, 5117.

(77) Berthet, J.-C.; Thuéry, P.; Dognon, J.-P.; Guillaneux, D.; Ephritikhine, M. Inorg. Chem. 2008, 47, 6850.

(78) Ionova, G.; Rabbe, C.; Guillaumont, R.; Ionov, S.; Madic, C.; Krupa, J.-C.; Guillaneux, D. New J. Chem. 2002, 26, 234.

(79) Benay, G.; Schurhammer, R.; Wipff, G. Phys. Chem. Chem. Phys. 2010, 12, 11089.

(80) (a) Chevrot, G.; Schurhammer, R.; Wipff, G. Phys. Chem. Chem. Phys. 2007, 9, 1991. (b) Chevrot, G.; Schurhammer, R.; Wipff, G. Phys. Chem. Chem. Phys. 2007, 9, 5928 .

(81) (a) Madic, C.; Hudson, M. J.; Liljenzin, J.-O.; Glatz, J.P.; Nannicini, R.; Facchini, A.; Kolarik, Z.; Odoj, R. Prog. Nucl. Energ. 2002, 40, 523. (b) Madic, C.; Boullis, B.; Baron, P.; Testard, F.; Hudson, M. J.; Liljenzin, J.-O.; Christiansen, B.; Ferrando, M.; Facchini, A.; Geist, A.; Modolo, G.; Espartero, A. G.; De Mendoza, J. J. Alloys Compd. 2007, 444-445, 23.

(82) (a) Wei, Y.-Z.; Hoshi, H.; Kumagai, M.; Asakura, T.; Morita, Y. J. Alloys Compd. 2004, 374, 447. (b) Bhattacharyya, A.; Mohapatra, P. K.; Roy, A.; Gadly, T.; Ghosh, S. K.; Manchanda, V. K. Hydrometallurgy 2009 , 99, 18.

(83) (a) Madic, C.; Hudson, M. J.; Liljenzin, J.-O.; Glatz, J.P.; Nannicini, R.; Facchini, A.; Kolarik, Z.; Odoj, R. New Partitioning Techniques for Minor Actinides. EUR19149EN (2000). (b) Hill, C.; Guillaneux, D.; Berthon, L.; Madic, C. J. Nucl. Sci. Technol. 2002, Supplement 3, 309.

(84) Nilsson, M.; Andersson, S.; Ekberg, C.; Foreman, M. R. S.; Hudson, M. J.; Skarnemark, G. Radiochim. Acta 2006, 94, 103 .

(85) Hudson, M. J.; Foreman, M. R. St. J.; Hill, C.; Huet, N.; Madic, C. Solvent Extr. Ion Exch. 2003, 21, 637.

(86) Case, F. H. J. Org. Chem. 1965, 30, 931.

(87) (a) Fife, W. K. J. Org. Chem. 1983, 48, 1375. (b) Norrby, T.; Börje, A.; Zhang, L.; Åkermark, B. Acta Chem. Scand. 1998, 52, 77.

(88) Hudson, M. J.; Drew, M. G. B.; Foreman, M. R. St J.; Hill, C.; Huet, N.; Madic, C.; Youngs, T. G. A. Dalton
Trans. 2003, 1675.

(89) Krejzler, J.; Narbutt, J.; Foreman, M. R. St J.; Hudson, M. J.; Casensky, B.; Madic, C. Czech. J. Phys. 2006, 56, D459.

(90) Girnt, D.; Roesky, P. W.; Geist, A.; Ruff, C. M.; Panak, P. J.; Denecke, M. A. Inorg. Chem. 2010, 49, 9627.

(91) Drew, M. G. B.; Foreman, M. R. St J.; Geist, A.; Hudson, M. J.; Marken, F.; Norman, V.; Weigl, M. Polyhedron 2006, 25, 888.

(92) Drew, M. G. B.; Hill, C.; Hudson, M. J.; Iveson, P. B.; Madic, C.; Youngs, T. G. A. Dalton Trans. 2004, 244.

(93) $\mathrm{p}$

(94) $\mathrm{p}$

(95) Drew, M. G. B.; Foreman, M. R. S. J.; Hill, C.; Hudson, M. J.; Madic, C. Inorg. Chem. Commun. 2005, 8, 239.

(96) Narbutt, J.; Krejzler, J. Radiochim. Acta 2008, 96, 219.

(97) Foreman, M. R. S.; Hudson, M. J.; Drew, M. G. B.; Hill, C.; Madic, C. Dalton Trans. 2006, 1645.

(98) Hubscher-Bruder, V.; Haddaoui, J.; Bouhroum, S.; Arnaud-Neu, F. Inorg. Chem. 2010, 49, 1363.

(99) Retegan, T.; Berthon, L.; Ekberg, C.; Fermvik, A.; Skarnemark, G.; Zorz, N. Solvent Extr. Ion Exch. 2009, 27, 663 .

(100) (a) Foreman, M. R. St. J.; Hudson, M. J.; Geist, A.; Madic, C.; Weigl, M. Solvent Extr. Ion Exch. 2005, 23, 645. (b) Nilsson, M.; Andersson, S.; Drouet, F.; Ekberg, C.; Foreman, M.; Hudson, M.; Liljenzin, J.-O.; Magnusson, D.; Skarnemark, G. Solvent Extr. Ion Exch. 2006, 24, 299.

(101) Nilsson, M.; Ekberg, C.; Foreman, M.; Hudson, M.; Liljenzin, J.-O.; Modolo, G.; Skarnemark, G. Solvent Extr. Ion Exch. 2006, 24, 823.

(102) Retegan, T.; Ekberg, C.; Dubois, I.; Fermvik, A.; Skarnemark, G.; Wass, T. J. Solvent Extr. Ion Exch. 2007, 25, 417.

(103) Ekberg, C.; Dubois, I.; Fermvik, A.; Retegan, T.; Skarnemark, G.; Drew, M. G. B.; Foreman, M. R. S.; Hudson, M. J. Solvent Extr. Ion Exch. 2007, 25, 603.

(104) Geist, A.; Hill, C.; Modolo, G.; Foreman, M. R. St. J.; Weigl, M.; Gompper, K.; Hudson, M. J. Solvent Extr. Ion Exch. 2006, 24, 463.

(105) Magnusson, D.; Christiansen, B.; Glatz, J.-P.; Malmbeck, R.; Modolo, G.; Serrano-Purroy, D.; Sorel, C. Radiochim. Acta 2009, 97, 155.

(106) (a) Malmbeck, R.; Magnusson, D.; Glatz, J.-P. in Proceedings of Global 2009, Paris, France, 2009, paper 1937. (b) Magnusson, D.; Christiansen, B.; Foreman, M. R. S.; Geist, A.; Glatz, J.-P.; Malmbeck, R.; Modolo, G.; Serrano-Purroy, D.; Sorel, C. Solvent Extr. Ion Exch. 2009, 27, 97.

(107) Aneheim, E.; Ekberg, C.; Fermvik, A.; Foreman, M. R. St. J.; Retegan, T.; Skarnemark, G. Solvent Extr. Ion Exch. 2010, 28, 437.

(108) Berthet, J.-C.; Thuéry, P.; Foreman, M. R. S.; Ephritikhine, M. Radiochim. Acta 2008, 96, 189.

(109) (a) Berthet, J.-C.; Siffredi, G.; Thuéry, P. ; Ephritikhine, M. Dalton Trans. 2009, 3478. (b) Berthet, J.-C.; Maynadié, J.; Thuéry, P. ; Ephritikhine, M. Dalton Trans. 2010, 39, 6801.

(110) Trumm, S.; Lieser, G.; Foreman, M. R. S. J.; Panak, P. J.; Geist, A.; Fanghänel, T. Dalton Trans. 2010, 39, 923.

(111) Benay, G.; Schurhammer, R.; Wipff, G. Phys. Chem. Chem. Phys. 2011, 13, 2922.

(112) Lewis, F. W.; Harwood, L. M.; Hudson, M. J.; Drew, M. G. B.; Modolo, G.; Sypula, M.; Desreux, J. F.; Bouslimani, N.; Vidick, G. Dalton Trans. 2010, 39, 5172 .

(113) (a) Mincher, B. J.; Modolo, G.; Mezyk, S. P. Solvent Extr. Ion Exch. 2009, 27, 1. (b) Mincher, B. J.; Modolo, 
G.; Mezyk, S. P. Solvent Extr. Ion Exch. 2009, 27, 331. (c) Mincher, B. J.; Modolo, G.; Mezyk, S. P. Solvent Extr. Ion Exch. 2009, 27, 579. (d) Mincher, B. J.; Modolo, G.; Mezyk, S. P. Solvent Extr. Ion Exch. 2010, $28,415$.

(114) Buxton, G. V.; Greenstock, C. L.; Helman, W. P.; Ross, A. B. J. Phys. Chem. Ref. Data 1988, 17, 513.

(115) Spinks, J. W. T.; Woods, R. J. in An Introduction to Radiation Chemistry, 3rd ed, John Wiley and Sons: New York, 1990.

(116) Fermvik, A.; Berthon, L.; Ekberg, C.; Englund, S.; Retegan, T.; Zorz, N. Dalton Trans. 2009, 6421.

(117) Hudson, M. J.; Boucher, C. E. ; Braekers, D. ; Desreux, J. F. ; Drew, M. G. B. ; Foreman, M. R. St J.; Harwood, L. M.; Hill, C.; Madic, C.; Marken, F.; Youngs, T. G. A. New J. Chem. 2006, 30, 1171.

(118) Ekberg, C.; Aneheim, E.; Fermvik, A.; Foreman, M.; Löfström-Engdahl, E.; Retegan, T.; Spendlikova, I. J. Chem. Eng. Data 2010, 55, 5133.

(119) Retegan, T.; Ekberg, C.; Englund, S.; Fermvik, A.; Foreman, M. R. S.; Skarnemark, G. Radiochim. Acta 2007, 95, 637.

(120) Fermvik, A.; Ekberg, C.; Englund, S.; Foreman, M. R. S. J.; Modolo, G.; Retegan, T.; Skarnemark, G. Radiochim. Acta 2009, 97, 319.

(121) Magnusson, D.; Christiansen, B.; Malmbeck, R.; Glatz, J.-P. Radiochim. Acta 2009, 97, 497.

(122) (a) Coffman, D. D.; Jenner, E. L.; Lipscomb, R. D. J. Am. Chem. Soc. 1958, 80, 2864. (b) Bremner, D. H.; Mitchell, S. R.; Staines, H. Ultrasonics Sonochemistry 1996, 3, 47. (c) Bremner, D. H.; Burgess, A. E.; Li, F.-B. Green Chem. 2001, 3, 126.

(123) (a) Jones, P.; Villeneuve, G. B.; Fei, C.; DeMarte, J.; Haggarty, A. J.; Nwe, K. T.; Martin, D. A.; Lebuis, A.M.; Finkelstein, J. M.; Gour-Salin, B. J.; Chan, T. H.; Leyland-Jones, B. R. J. Med. Chem. 1998, 41, 3062. (b) Kikuchi, K.; Hibi, S.; Yoshimura, H.; Tokuhara, N.; Tai, K.; Hida, T.; Yamauchi, T.; Nagai, M. J. Med. Chem. 2000, 43, 409.

(124) Harwood, L. M.; Hudson, M. J.; Lewis, F. W. GB0922588.9 (2009).

(125) For a similar reaction, see: Ibarzo, J.; Ortuña, R. M. Tetrahedron 1994, 50, 9825. 
Frank W. Lewis was born in Dublin, Ireland in 1976. He graduated with a BA in Chemistry at Trinity College Dublin in 1998. After a period of self-employment, he commenced graduate studies with Prof. David Grayson at Trinity College Dublin where he obtained his $\mathrm{PhD}$ in organic chemistry in 2008. He is currently a postdoctoral fellow in the group of Prof. Laurence Harwood at the University of Reading, UK where he is working on the design and synthesis of ligands for the selective extraction of minor actinides from nuclear waste solutions. His research interests are asymmetric synthesis, sulfone chemistry and ligand design.

Michael J. Hudson studied chemistry at University College London where he obtained his PhD in 1965 . He has published over 100 refereed papers on separation processes that involve precious metals, actinides and base metals. He was awarded the DSc from the University of London in 2000. He has received extensive financial support for the partitioning of minor actinides from the lanthanide elements. He was responsible for the design and development of many heterocyclic molecules including the BTBP molecules, which are discussed later in this review.

\title{
Laurence M. Harwood ppp
}

\section{Development of Highly Selective Ligands for Separations of Actinides from Lanthanides in the Nuclear Fuel Cycle}

\author{
Graphical Abstract
}

\section{Manuscript submission checklist}

- Statement of significance of work.

- Full mailing address, telephone, and fax numbers, and email address of the corresponding author.

- Graphical abstract.

- 5 key words.

- Paper saved as a PDF file.

- Original Word file.

- Original graphics files.

- Biographical sketches of the authors.

- Photographs of the authors, if not included the hardcopies should be sent by regular mail to the Editorial Office after the manuscript is accepted.

Send all materials on this list to the Editor-in-Chief. Keep the original Word and graphics files for revisions and for final submission after acceptance. 


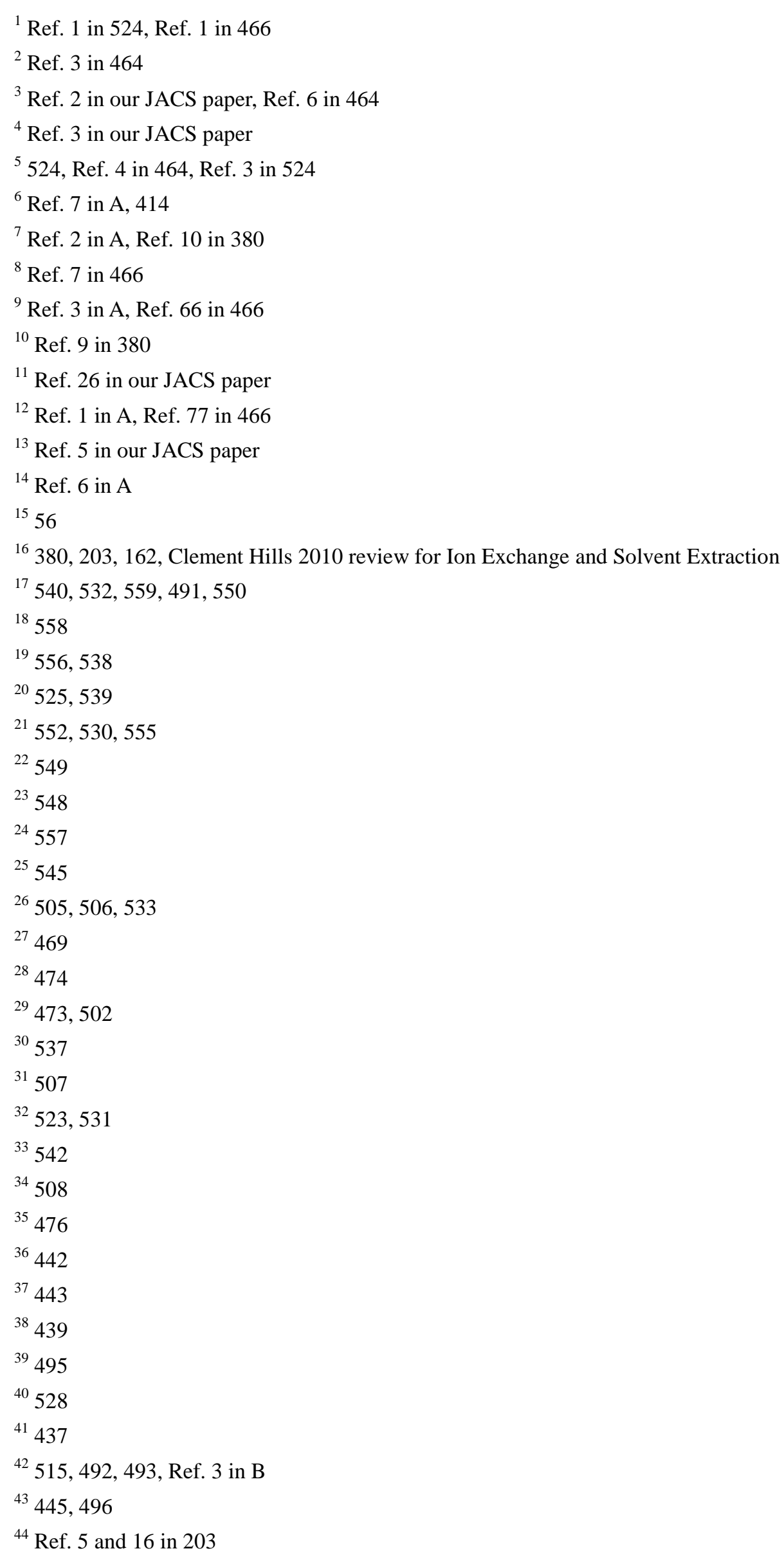

${ }^{1}$ Ref. 1 in 524, Ref. 1 in 466

Ref. 3 in 464

${ }^{3}$ Ref. 2 in our JACS paper, Ref. 6 in 464

${ }^{4}$ Ref. 3 in our JACS paper

524 , Ref. 4 in 464, Ref. 3 in 524

${ }^{6}$ Ref. 7 in A, 414

Ref. 2 in A, Ref. 10 in 380

${ }^{8}$ Ref. 7 in 466

${ }^{9}$ Ref. 3 in A, Ref. 66 in 466

${ }^{10}$ Ref. 9 in 380

${ }^{11}$ Ref. 26 in our JACS paper

${ }^{12}$ Ref. 1 in A, Ref. 77 in 466

${ }^{13}$ Ref. 5 in our JACS paper

${ }^{14}$ Ref. 6 in A

${ }^{15} 56$

${ }^{16}$ 380, 203, 162, Clement Hills 2010 review for Ion Exchange and Solvent Extraction

${ }^{17} 540,532,559,491,550$

${ }^{18} 558$

${ }^{19} 556,538$

525,539

${ }^{21} 552,530,555$

${ }^{22} 549$

${ }^{23} 548$

${ }^{24} 557$

545

${ }^{26} 505,506,533$

${ }^{27} 469$

${ }^{28} 474$

${ }^{29} 473,502$

${ }^{30} 537$

${ }^{31} 507$

${ }^{32} 523,531$

${ }^{33} 542$

${ }^{34} 508$

${ }^{35} 476$

${ }^{36} 442$

${ }^{37} 443$

${ }^{38} 439$

${ }^{39} 495$

437

${ }^{43} 445,496$

${ }^{44}$ Ref. 5 and 16 in 203 


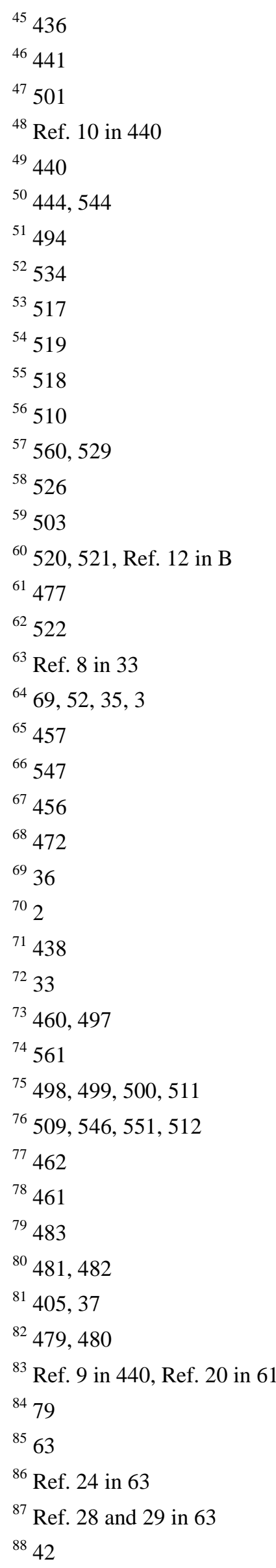




\section{${ }^{89} 57$ \\ ${ }^{90} 513$ \\ ${ }^{91} 39$ \\ 9241}

${ }^{93}$ See lab notebook for Refs.

${ }^{94} 140,152,316$

${ }^{95} 40$

${ }^{96} 217$

${ }^{97} 38$

${ }^{98} 381$

${ }^{99} 554$

${ }^{100} 62,60$

${ }^{101} 59$

${ }^{102} 211$

${ }^{103} 58$

${ }^{104} 61$

${ }^{105} 543$

${ }^{106} 243,212$

${ }^{107} 553$

${ }^{108} 216$

${ }^{109} 458,478$

${ }^{110} 459$

${ }^{111} 562$

${ }^{112}$ Our 2010 Dalton paper

${ }^{113} 464,465,466,467$

${ }^{114}$ Ref. 31 in 464

${ }^{115}$ Ref. 35 in 464

${ }^{116} 261$

${ }^{117} 1$

${ }^{118} 488$

${ }^{119} 215$

${ }^{120} 214$

${ }^{121} 536$

${ }^{122} 71$, Ref. 14 in our Dalton paper

${ }^{123} 45,75$

${ }^{124}$ Our CyMe4-diketone patent

${ }^{125}$ For a similar reaction, see Ref. 20 in our JACS paper 